\title{
Diastereocontrol in Radical Addition to $\beta$-Benzyloxy Hydrazones: Revised Approach to Tubuvaline and Synthesis of $O$-Benzyltubulysin V Benzyl Ester
}

\author{
Manshu Li, Koushik Banerjee, and Gregory K. Friestad* \\ Department of Chemistry, University of Iowa, Iowa City, Iowa 52242 USA \\ email: gregory-friestad@uiowa.edu
}

Supporting Information

\section{Contents}

Brief Review of Synthetic Approaches to Tubuvaline and Tubulysins $\quad$ S2

${ }^{1} \mathrm{H}$ NMR and ${ }^{13} \mathrm{C}$ NMR Spectra for New Compounds $\quad$ S8

$\begin{array}{ll}\text { Enantiomer Ratio and Configuration Assignment of }(R)-\mathbf{1 9} & \text { S49 }\end{array}$ 


\section{Brief Review of Synthetic Approaches to Tubuvaline and Tubulysins}

To put the present tubulysin study into a larger context, we briefly review the diverse and creative strategies that complement our work. The primary drivers of innovation tend to focus on stereocontrol at the alcohol- or ester-bearing center at $\mathrm{C} 11$, stereocontrol at the $\mathrm{C} 13$ chiral amine, and introduction of the thiazole.

In Wipf's route to a Tuv-Tup dipeptide,,$^{1}$ the Tuv $\mathrm{C} 13$ stereocenter was obtained from valine, while the $\mathrm{C} 11 \mathrm{OH}$ was installed by substrate-controlled enolate oxidation; a multistep dipeptide cyclodehydration sequence was applied to construct the thiazole. A revised approach, en route to $N_{14}$-desacetoxytubulysin $\mathrm{H},{ }^{2}$ employed thiazole anion addition to a homovalinal derivative, generating alcohol A (dr 2:1). An oxidation and reduction sequence corrected the configuration of the undesired diastereomer. ${ }^{3}$

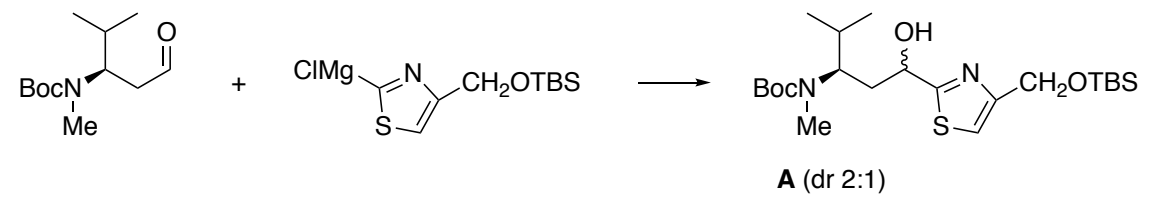

Dömling and Wessjohann reported total synthesis of C2-epi-tubulysins $\mathrm{U}$ and $\mathrm{V},{ }^{4}$ with the Tuv C13 configuration originating in a valine derivative. A multicomponent reaction (MCR) constructed the thiazole B with modest stereocontrol at C11 (dr 75:25). A similar MCR approach to Tuv was used in the 2009 synthesis of tubulysin B by Wessjohann et al. ${ }^{5}$ More recently, a catalytic asymmetric Passerini reaction MCR was achieved by Dömling et al. with good stereoselectivity (dr 92:8), and dehydrative cyclization to the thiazole and acyl transfer gave the Mep-Ile-Tuv tripeptide of tubulysins. ${ }^{6}$

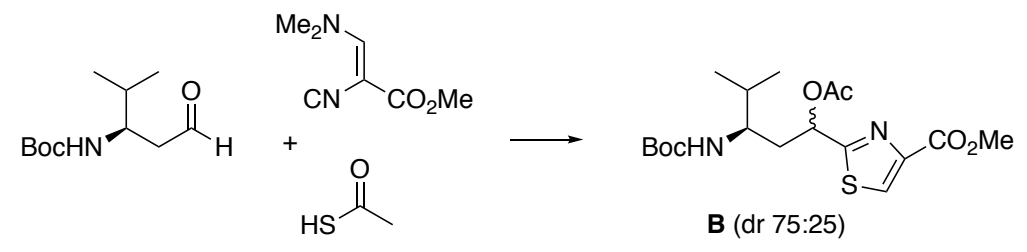

Ellman reported the first total synthesis of tubulysin D in 2006 using a strategy that constructed the $\mathrm{C} 11$ and $\mathrm{C} 13$ stereocenters of Tuv by sequential metalloenamine aldol addition and hydride reduction. ${ }^{7}$ Both reactions employed the $N$-sulfinyl group as a chiral auxiliary, and the sequence 
afforded tubuvaline precursor $\mathbf{C}$ with 92:8 and 91:9 diastereomer ratios at $\mathrm{C} 11$ and $\mathrm{C} 13$, respectively.
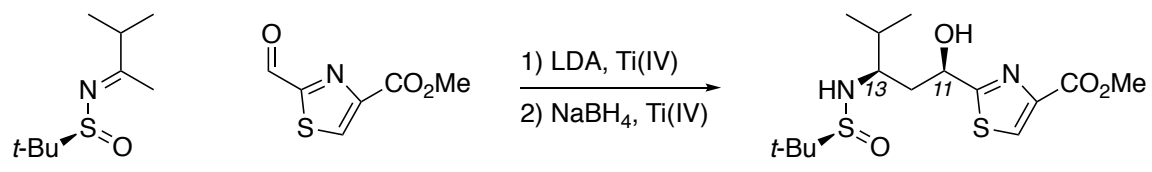

C (dr 92:8 at C11, 91:9 at C13)

In 2007, Zanda reported a total synthesis of tubulysin U and V. ${ }^{8}$ The Tuv C13 stereocenter was constructed via racemic aza-Michael addition, with C11 controlled by oxazaborolidine-catalyzed (“CBS") borane reduction of a $\beta$-aminoketone. This led to a separable mixture of $\mathbf{X X}$ and 13-epi$\mathbf{X X}$ in $67 \%$ yield. Zanda also reported a Mannich addition to generate the racemic $\beta$-aminoketone that was then reduced as before. ${ }^{9}$
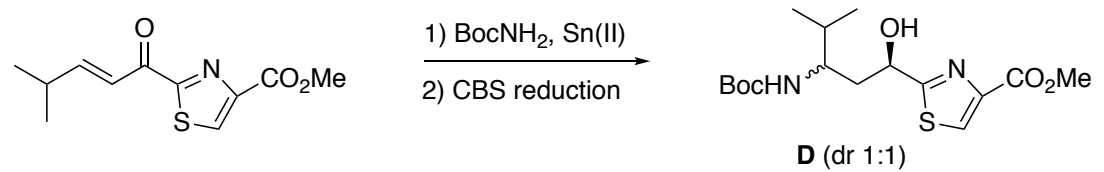

A gram-scale synthesis of Tuv-Tup dipeptide fragment was reported by Chandrasekhar in $2009 .{ }^{10}$ The C13 stereocenter (Tuv numbering) originated in $L$-valine, while the C11 alcohol was constructed by organocatalytic $\alpha$-hydroxylation to afford $\mathbf{E}$ with excellent diastereoselectivity. After functional group manipulations, condensation with a cysteine derivative and oxidation afforded the thiazole.

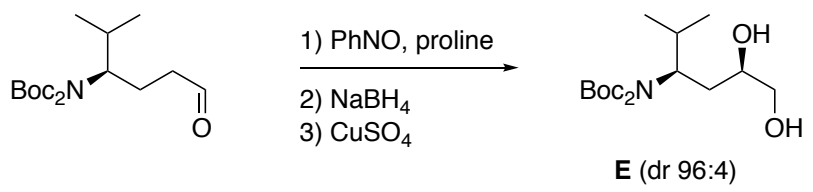

Fecik reported syntheses of several simplified tubulysin analogs in 2008, revealing the importance of the C11 stereocenter to cytotoxic potency. ${ }^{11}$ The C13 stereocenter in the Tuv fragment was obtained from a natural source, while C11 was generated in the ketone oxidation state via addition to a Weinreb amide to furnish $\mathbf{F}$, a thiazolyl ketone analog of Tuv. CBS reduction was then employed to control the C11 configuration. The 2009 synthesis by Kazmaier and Müller of a C11 des-acetoxy tubulysin analog, termed pretubulysin for its proposed biosynthetic role, confirmed the importance of the Tuv C11 functionality; its absence diminished the potency ten- 
fold. ${ }^{12}$ The Weinreb amide approach of Fecik was also used by Parker et al. en route to a tubulysin analog as payload for antibody-drug conjugates. ${ }^{13}$

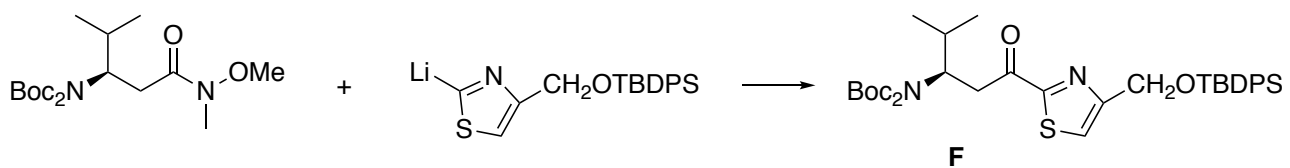

Tamura et al. exploited a diastereoselective 1,3-dipolar nitrone cycloaddition to introduce the C11 and C13 stereocenters using both $D$-gulosyl and camphorsultam chiral auxiliaries, setting both of the configurations in $\mathbf{G} .{ }^{14}$ The thiazole moiety was established in a multistep sequence, and NO bond cleavage of the isoxazolidine ring then afforded Tuv methyl ester.

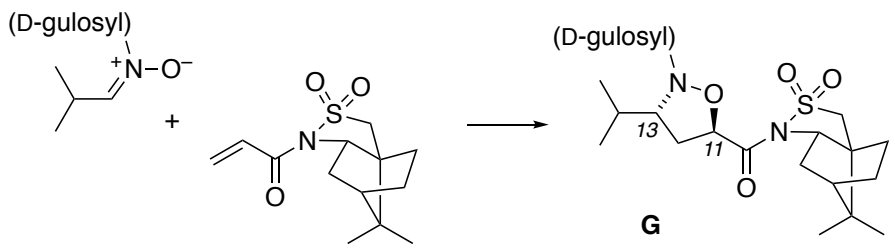

Chen targeted tubulysin $\mathrm{U}$ and its C4 epimer, employing a Tuv synthesis via thiazolyl ketone enolate addition to a chiral sulfinimine to generate the $\mathrm{C} 13$ configuration (dr $103: 1) .{ }^{15}$ Diastereoselective reduction of the ketone led to Tuv fragment $\mathbf{H}$ (dr 10:1).

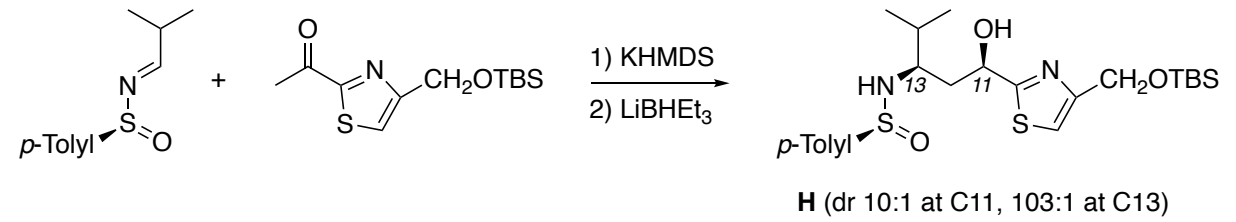

The synthesis of tubulysin V reported in 2013 by Lin et al. exploited allyl addition to chiral sulfinimines to generate homovalinal, setting the C13 stereocenter (dr 96:4), and then adopted the previously described Wessjohann multicomponent coupling to prepare the thiazole and install the C11 configuration (dr 1:2.4). ${ }^{16}$

In 2016, Nicolaou reported syntheses of numerous tubulysin analogues, with the Tuv C13 stereocenter sourced from valine.${ }^{17}$ Reminiscent of the Wipf approach, a coupling of a homovalinal derivative with a thiazole nucleophile was enabled in this case by $\mathrm{C}-\mathrm{H}$ activation. The $\mathrm{C} 11$ stereocenter was constructed by CBS reduction. 
Other approaches to tubuvaline and analogs include a proline-catalyzed aldol reaction followed by substrate-controlled reductive amination, ${ }^{18}$ asymmetric hetero-Diels-Alder reaction and reductive amination to generate a constrained tubuvaline analog, ${ }^{19}$ and addition of isopropyl Grignard to a $\beta$-alkoxysulfinimine. ${ }^{20}$

Table S1. Comparison of C11 and C13 stereocontrol in Tuv syntheses.

\begin{tabular}{|c|c|c|}
\hline Contributor, Year & C11 Stereocontrol & C13 Stereocontrol \\
\hline Friestad, 2004 & Enolate allylation, >98:2 & Radical addition to $\mathrm{C}=\mathrm{N},>98: 2$ \\
\hline Wipf 2004 & Enolate oxidation, $>98: 2$ & (natural source) \\
\hline Dömling, 2006 & MCR, 1:2.4 & (natural source) \\
\hline Ellman, 2006 & Metalloenamine aldol, 92:8 & Sulfinimine reduction, $91: 9$ \\
\hline Zanda, 2007 & CBS reduction, 95:5 & aza-Michael, 1:1 \\
\hline Wipf, 2007 & 1,3-Diastereocontrol, 2:1 & (natural source) \\
\hline Fecik, 2009 & CBS reduction, $>98: 2^{a}$ & (natural source) \\
\hline Chandrasekhar, 2009 & Enamine oxidation, $96: 4$ & (natural source) \\
\hline Tamura, 2009 & \multicolumn{2}{|c|}{ Both $\mathrm{C} 11$ and $\mathrm{C} 13$ by nitrone cycloaddition, $85: 15$} \\
\hline Chen, 2013 & Borohydride reduction, 10:1 & Mannich, 103:1 \\
\hline Lin, 2013 & (natural source) & Allylindium addition to $\mathrm{C}=\mathrm{N}, 96: 4$ \\
\hline Wei, 2016 & MCR, 1:2.4 & $\mathrm{i}-\mathrm{PrMgBr}$ addition to $\mathrm{C}=\mathrm{N}, 98: 2$ \\
\hline Nicolau, 2016 & CBS reduction, $>98: 2^{\mathrm{b}}$ & (natural source) \\
\hline Friestad, this work & Keck allylation, 10:1 & Radical addition to $\mathrm{C}=\mathrm{N},>98: 2$ \\
\hline
\end{tabular}

a Almost exclusively one configuration, ratio not reported

b Single diastereomer after purification, ratio not reported

Table S2. Comparison of C2 and C4 stereocontrol in Tup syntheses.

\begin{tabular}{|c|c|c|}
\hline Contributor, Year & C2 Stereocontrol & C4 Stereocontrol \\
\hline Friestad, 2004 & (natural source) & Radical addition to $\mathrm{C}=\mathrm{N},>98: 2$ \\
\hline Wipf 2004 & Hydrogenation, 3:1 & (natural source) \\
\hline Dömling, 2006 & Enolate alkylation, 19:81 & (commercial) \\
\hline Ellman, 2006 & \multicolumn{2}{|c|}{ Both $\mathrm{C} 2$ and $\mathrm{C} 4$ by reductive addition to acrylate, $80: 15: 3: 2$} \\
\hline Zanda, 2007 & Hydrogenation, 1:1 & (natural source) \\
\hline Fecik, 2009 & Enolate alkylation, $10: 1$ & (natural source) \\
\hline Chandrasekhar, 2009 & (natural source) & Enamine oxidation and $\mathrm{S}_{\mathrm{N}} 2,99: 1$ \\
\hline Tamura, 2009 & Evans aldol, $>98: 2$ & (natural source) \\
\hline Chen, 2013 & Enolate allylation, $97: 3^{a}$ & $\mathrm{BnMgBr}$ addition to $\mathrm{C}=\mathrm{N}, 6.6: 1$ \\
\hline Lin, 2013 & Inversion via enolate, $6: 1$ & Allylzinc addition to $\mathrm{C}=\mathrm{N}, 95: 5$ \\
\hline Zanda, 2013 & Hydrogenation, 2:1 & (natural source) \\
\hline Wei, 2016 & Enolate alkylation, $>98: 2$ & Sulfinimine reduction, $>9: 1^{b}$ \\
\hline
\end{tabular}

${ }^{\text {a }}$ Ratio from literature cited by authors

${ }^{\mathrm{b}}$ Minor isomer separated, ratio not reported 


\footnotetext{
${ }^{1}$ Wipf, P.; Takada, T.; Rishel, M. J. Synthesis of the Tubuvaline-Tubuphenylalanine (Tuv-Tup) Fragment of Tubulysin. Org. Lett. 2004, 6, 4057-4060.

${ }^{2}$ Wipf, P.; Wang, Z. Total Synthesis of N14-Desacetoxytubulysin H. Org. Lett. 2007, 9, 1605-1607.

${ }^{3}$ Colombo, R.; Wang, Z.; Han, J.; Balachandran, R.; Daghestani, H. N.; Camarco, D. P.; Vogt, A.; Day, B. W.; Mendel, D.; Wipf, P. Total Synthesis and Biological Evaluation of Tubulysin Analogues. J. Org. Chem. 2016, 81, 10302-10320.

${ }^{4}$ Dömling, A.; Beck, B.; Eichelberger, U.; Sakamuri, S.; Menon, S.; Chen, Q.-Z.; Lu, Y.; Wessjohann, L. A. Total Synthesis of Tubulysin U and V. Angew. Chem. Int. Ed. 2006, 45, 7235-7239.

${ }^{5}$ Pando, O.; Dörner, S.; Preusentanz, R.; Denkert, A.; Porzel, A.; Richter, W.; Wessjohann, L. First Total Synthesis of Tubulysin B. Org. Lett. 2009, 11, 5567-5569.

${ }^{6}$ Vishwanatha, T. M.; Giepmans, B.; Goda, S. K.; Dömling, A. Tubulysin Synthesis Featuring Stereoselective Catalysis and Highly Convergent Multicomponent Assembly. Org. Lett. 2020, 22, 5396-5400.
}

${ }^{7}$ (a) Peltier, H. M.; McMahon, J. P.; Patterson, A. W.; Ellman, J. A. The Total Synthesis of Tubulysin D. J. Am. Chem. Soc. 2006, 128, 16018-16019. (b) Patterson, A. W.; Peltier, H. M.; Sasse, F.; Ellman, J. A., Design, Synthesis, and Biological Properties of Highly Potent Tubulysin D Analogues. Chem. Eur. J. 2007, 13 (34), 95349541. (c) Patterson, A. W.; Peltier, H. M.; Ellman, J. A. Expedient Synthesis of N-Methyl Tubulysin Analogues with High Cytotoxicity. J. Org. Chem. 2008, 73, 4362-4369.

${ }^{8}$ Sani, M.; Fossati, G.; Huguenot, F.; Zanda, M. Total Synthesis of Tubulysins U and V. Angew. Chem. Int. Ed. 2007, 46, 3526-3529.

${ }^{9}$ Shankar, S. P.; Jagodzinska, M.; Malpezzi, L.; Lazzari, P.; Manca, I.; Greig, I. R.; Sani, M.; Zanda, M. Synthesis and structure-activity relationship studies of novel tubulysin $\mathrm{U}$ analogues - effect on cytotoxicity of structural variations in the tubuvaline fragment. Org. Biomol. Chem. 2013, 11, 2273-2287.

${ }^{10}$ Chandrasekhar, S.; Mahipal, B.; Kavitha, M. Toward Tubulysin: Gram-Scale Synthesis of TubuvalineTubuphenylalanine Fragment. J. Org. Chem. 2009, 74, 9531-9534.

${ }^{11}$ Raghavan, B.; Balasubramanian, R.; Steele, J. C.; Sackett, D. L.; Fecik, R. A. Cytotoxic Simplified Tubulysin Analogues. J. Med. Chem. 2008, 51, 1530-1533.

${ }^{12}$ Ullrich, A.; Chai, Y.; Pistorius, D.; Elnakady, Y. A.; Herrmann, J. E.; Weissman, K. J.; Kazmaier, U.; Müller, R. Pretubulysin, a Potent and Chemically Accessible Tubulysin Precursor from Angiococcus disciformis. Angew. Chem. Int. Ed. 2009, 48, 4422-4425.

${ }^{13}$ (a) Parker, J. S.; McCormick, M.; Anderson, D. W.; Maltman, B. A.; Gingipalli, L.; Toader, D. The Development and Scale-Up of an Antibody Drug Conjugate Tubulysin Payload. Org. Process Res. Dev. 2017, 21, 1602-1609. (b) Toader, D.; Wang, F.; Gingipalli, L.; Vasbinder, M.; Roth, M.; Mao, S.; Block, M.; Harper, J.; Thota, S.; Su, M.; Ma, J.; Bedian, V.; Kamal, A. Structure-Cytotoxicity Relationships of Analogues of N14-Desacetoxytubulysin H. J. Med. Chem. 2016, 59, 10781-10787.

${ }^{14}$ (a) Shibue, T.; Hirai, T.; Okamoto, I.; Morita, N.; Masu, H.; Azumaya, I.; Tamura, O. Stereoselective synthesis of tubuvaline methyl ester and tubuphenylalanine, components of tubulysins, tubulin polymerization inhibitors.

Tetrahedron Lett. 2009, 50, 3845-3848. Shibue, T.; Hirai, T.; Okamoto, I.; Morita, N.; Masu, H.; Azumaya, I.; Tamura, O. Total Syntheses of Tubulysins. Chem. Eur. J. 2010, 16, 11678-11688.

${ }^{15}$ Yang, X.-D.; Dong, C.-M.; Chen, J.; Ding, Y.-H.; Liu, Q.; Ma, X.-Y.; Zhang, Q.; Chen, Y. Total Synthesis of Tubulysin U and Its C-4 Epimer. Chem. Asian J. 2013, 8, 1213-1222.

${ }^{16}$ Wang, R.; Tian, P.; Lin, G. Stereoselective Total Synthesis of Tubulysin V. Chin. J. Chem. 2013, 31, 40-48.

${ }^{17}$ (a) Nicolaou, K. C.; Yin, J.; Mandal, D.; Erande, R. D.; Klahn, P.; Jin, M.; Aujay, M.; Sandoval, J.; Gavrilyuk, J.; Vourloumis, D. Total Synthesis and Biological Evaluation of Natural and Designed Tubulysins. Journal of the American Chemical Society 2016, 138 (5), 1698-1708. (b) Nicolaou, K. C.; Erande, R. D.; Yin, J.; Vourloumis, D.; Aujay, M.; Sandoval, J.; Munneke, S.; Gavrilyuk, J. Improved Total Synthesis of Tubulysins and Design, Synthesis, and Biological Evaluation of New Tubulysins with Highly Potent Cytotoxicities against Cancer Cells as Potential Payloads for Antibody-Drug Conjugates. J. Am. Chem. Soc. 2018, 140, 3690-3711.

${ }^{18}$ Paladhi, S.; Das, J.; Samanta, M.; Dash, J. Asymmetric Aldol Reaction of Thiazole-Carbaldehydes: Regio- and Stereoselective Synthesis of Tubuvalin Analogues. Adv. Synth. Catal. 2014, 356, 3370-3376. 
${ }^{19}$ Park, Y.; Lee, J. K.; Ryu, J.-S. Synthesis of a Cyclic Analogue of Tuv N-Methyl Tubulysin. Synlett 2015, 26, 1063-1068.

${ }^{20}$ Tao, W.; Zhou, W.; Zhou, Z.; Si, C.-M.; Sun, X. Wei, B.-G. An enantioselective total synthesis of tubulysin V. Tetrahedron 2016, 72, 5928-5933. 


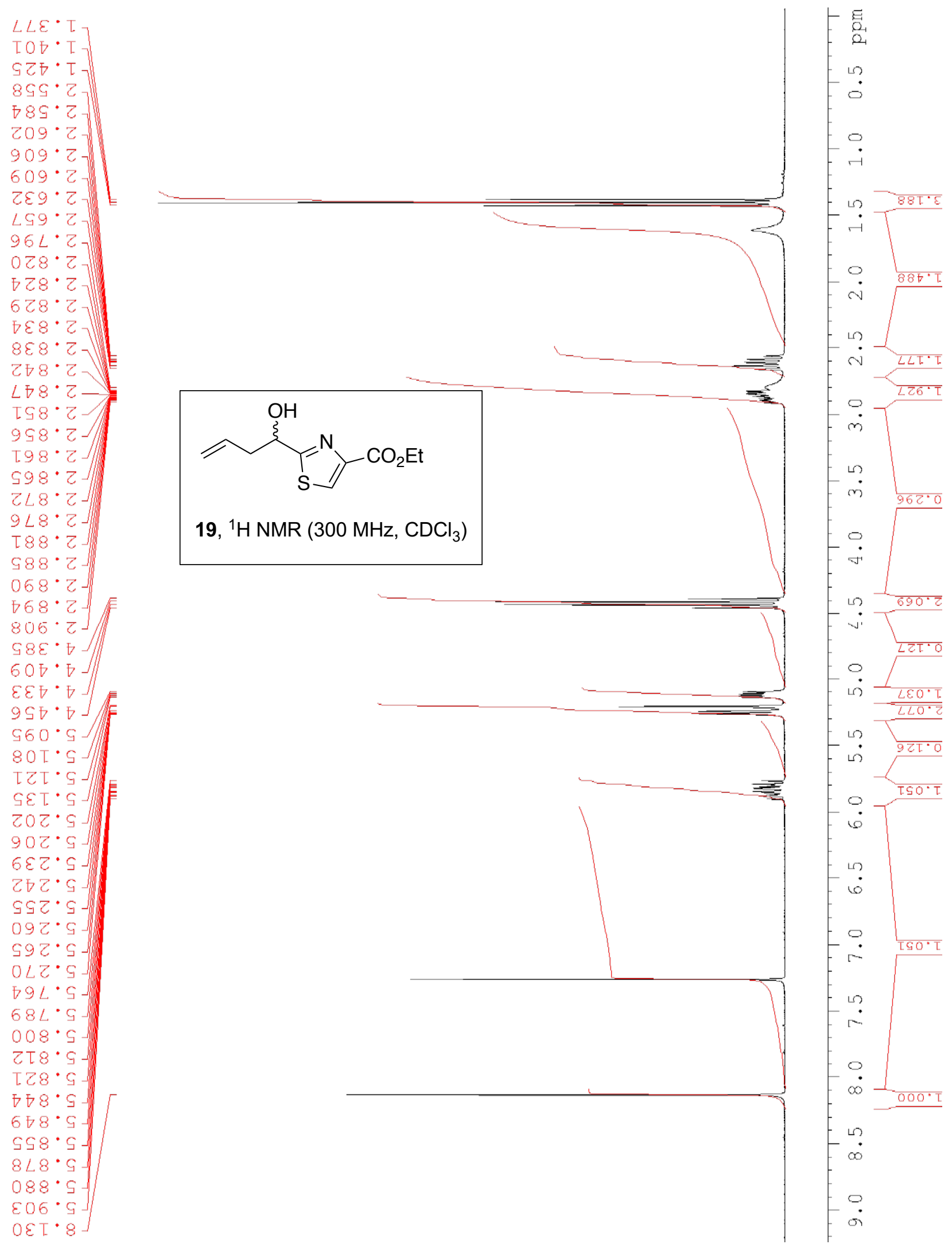




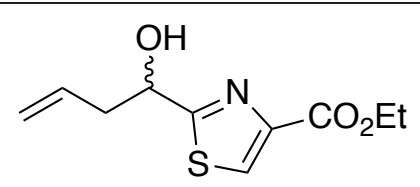

19, ${ }^{13} \mathrm{C}\left\{{ }^{1} \mathrm{H}\right\} \operatorname{NMR}\left(75 \mathrm{MHz}, \mathrm{CDCl}_{3}\right)$

こゅ・ฑて—

$027 \cdot 27$

$099^{*} \mathrm{Tg}$

$8 T 0 \cdot T L L$

$\mathrm{T} 69^{*} 6 \mathrm{TT}$

$\zeta L \nabla \cdot L 乙 \tau$

$\angle 98 \cdot 7 \varepsilon T$

$9 \varepsilon 6 \cdot 97 \tau \longrightarrow$

$279 \cdot \operatorname{Tg}$

$0 \tau 6 \cdot S L \tau$

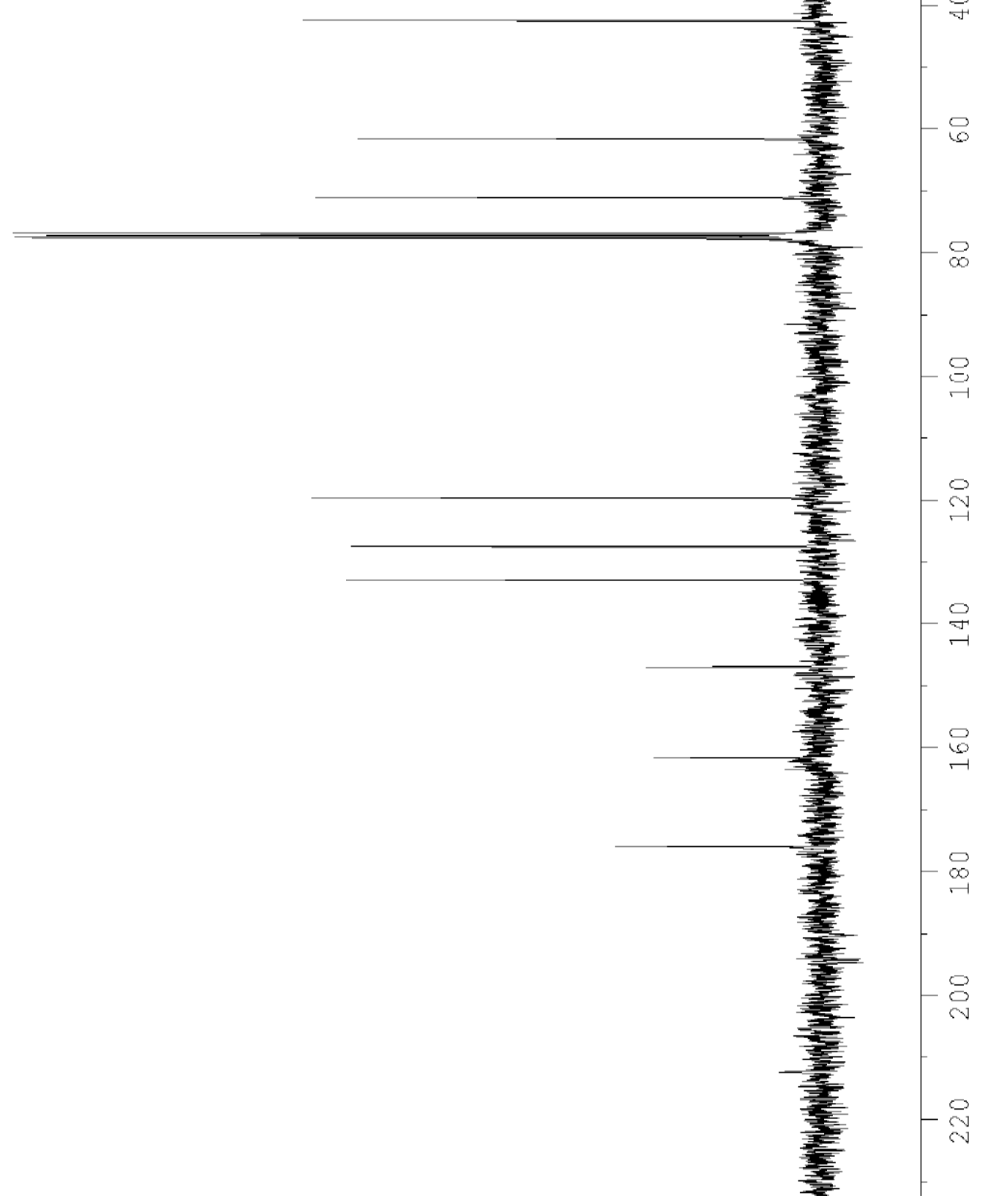



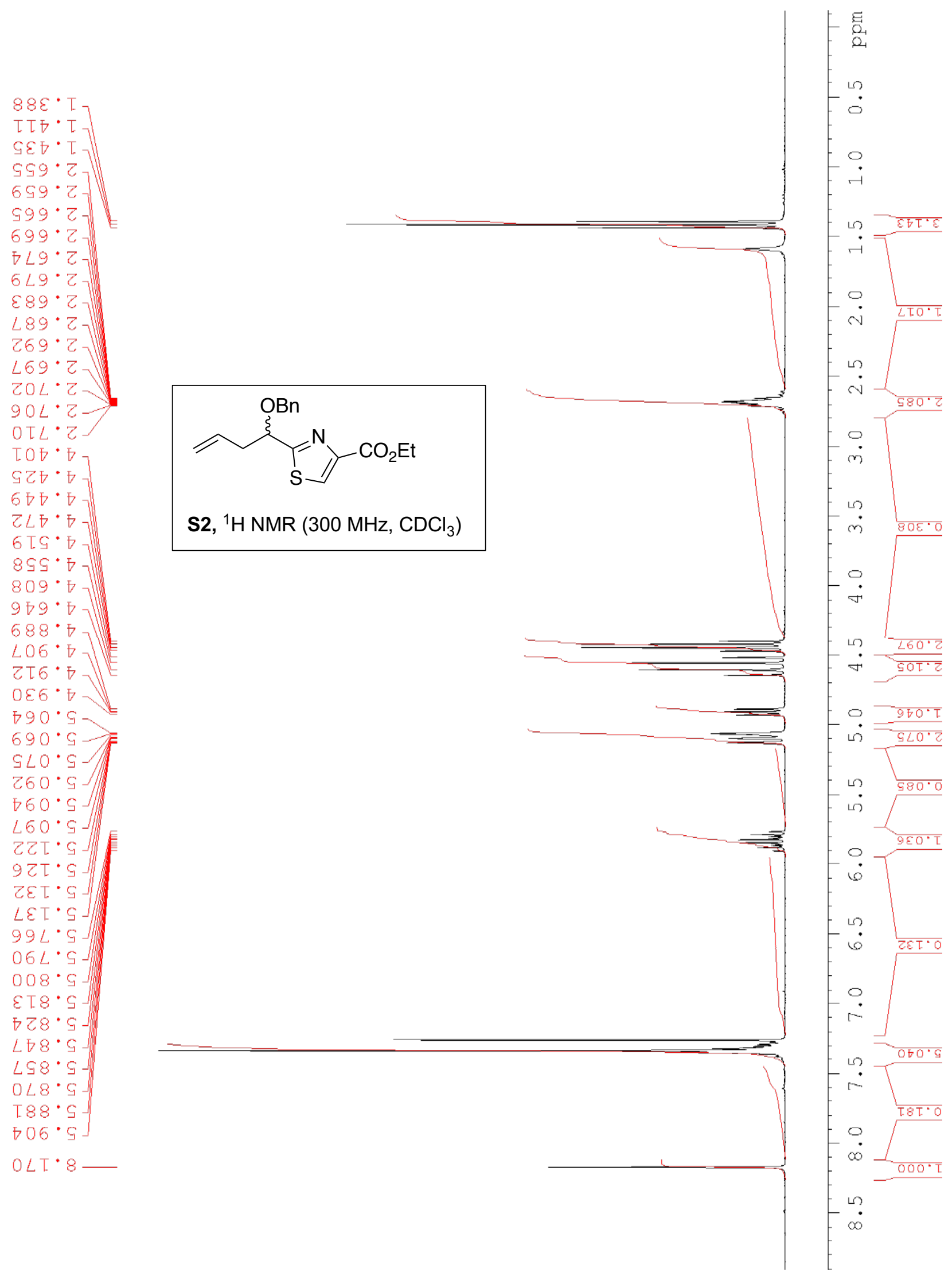


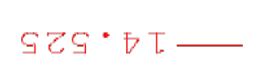

S2, ${ }^{13} \mathrm{C}\left\{{ }^{1} \mathrm{H}\right\} \mathrm{NMR}\left(75 \mathrm{MHz}, \mathrm{CDCl}_{3}\right)$

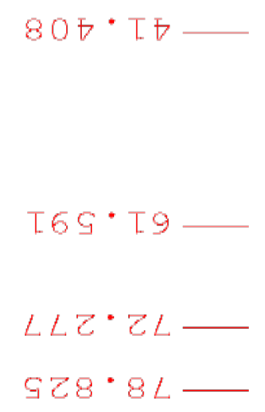

$267^{\circ} \cdot 8 T$

$\bar{\tau} 66^{\circ} \angle \tau T$

$\varepsilon \angle 0 \cdot 8 Z T-1$

$799 \cdot 8 \mathrm{CT}$

$L\llcorner 6 \cdot 2 \varepsilon \tau$

$\varepsilon 0 T^{\circ} \angle \varepsilon T \ldots$

$90 T \cdot L \nabla T$

$289 \cdot \mathrm{TgT}$

$008^{*} \nabla L \tau$
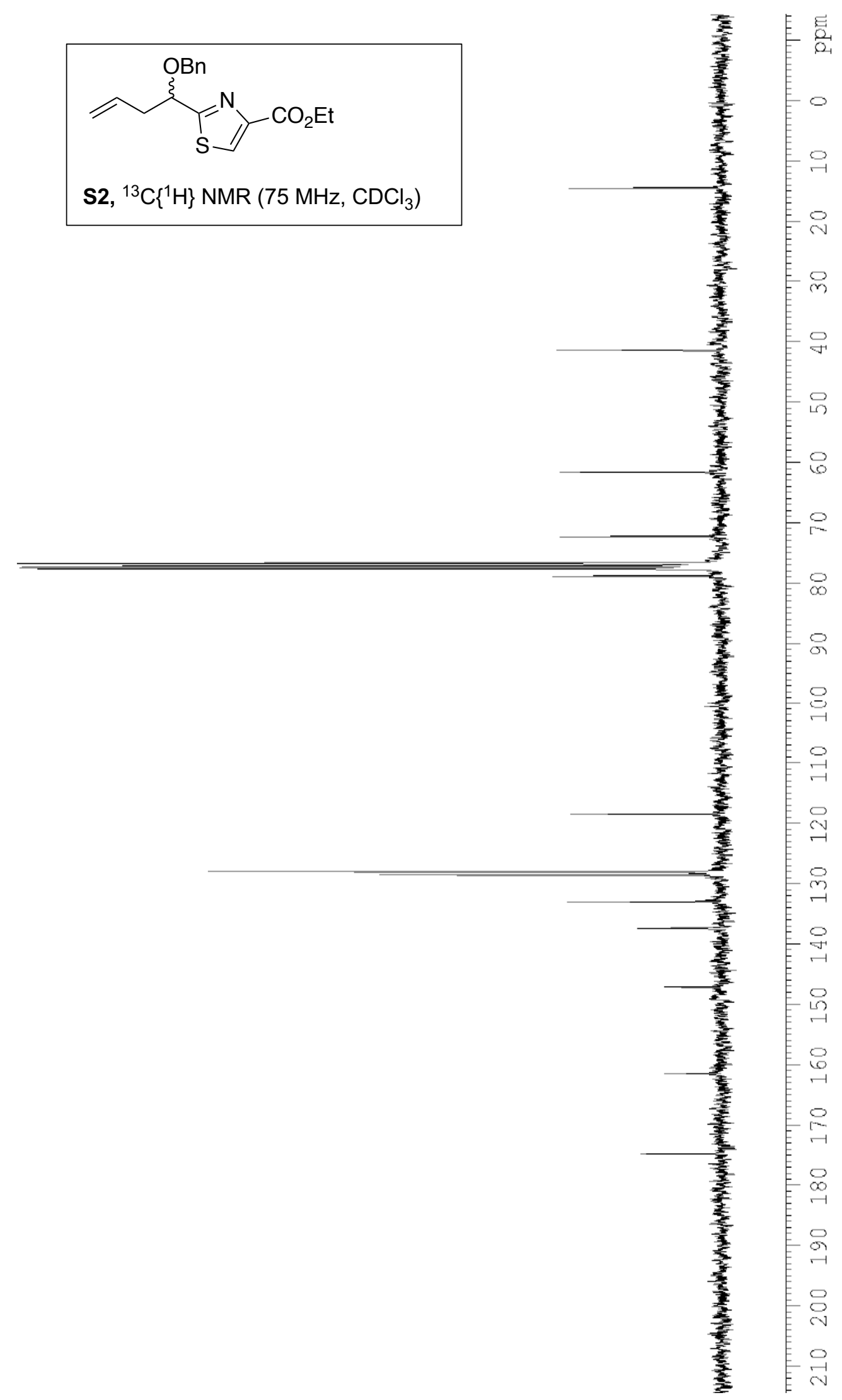

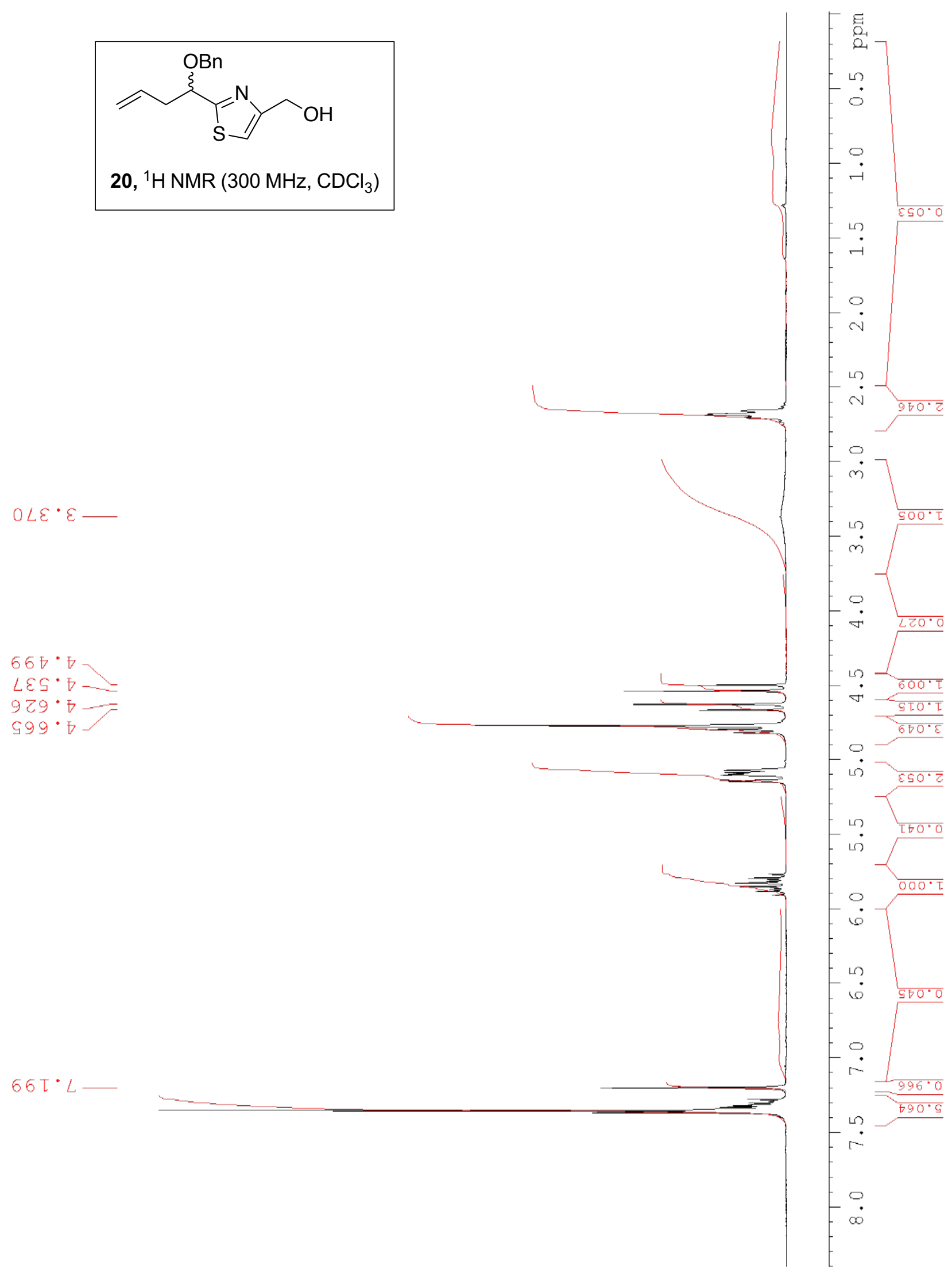

$66 \mathrm{~T} \cdot L$

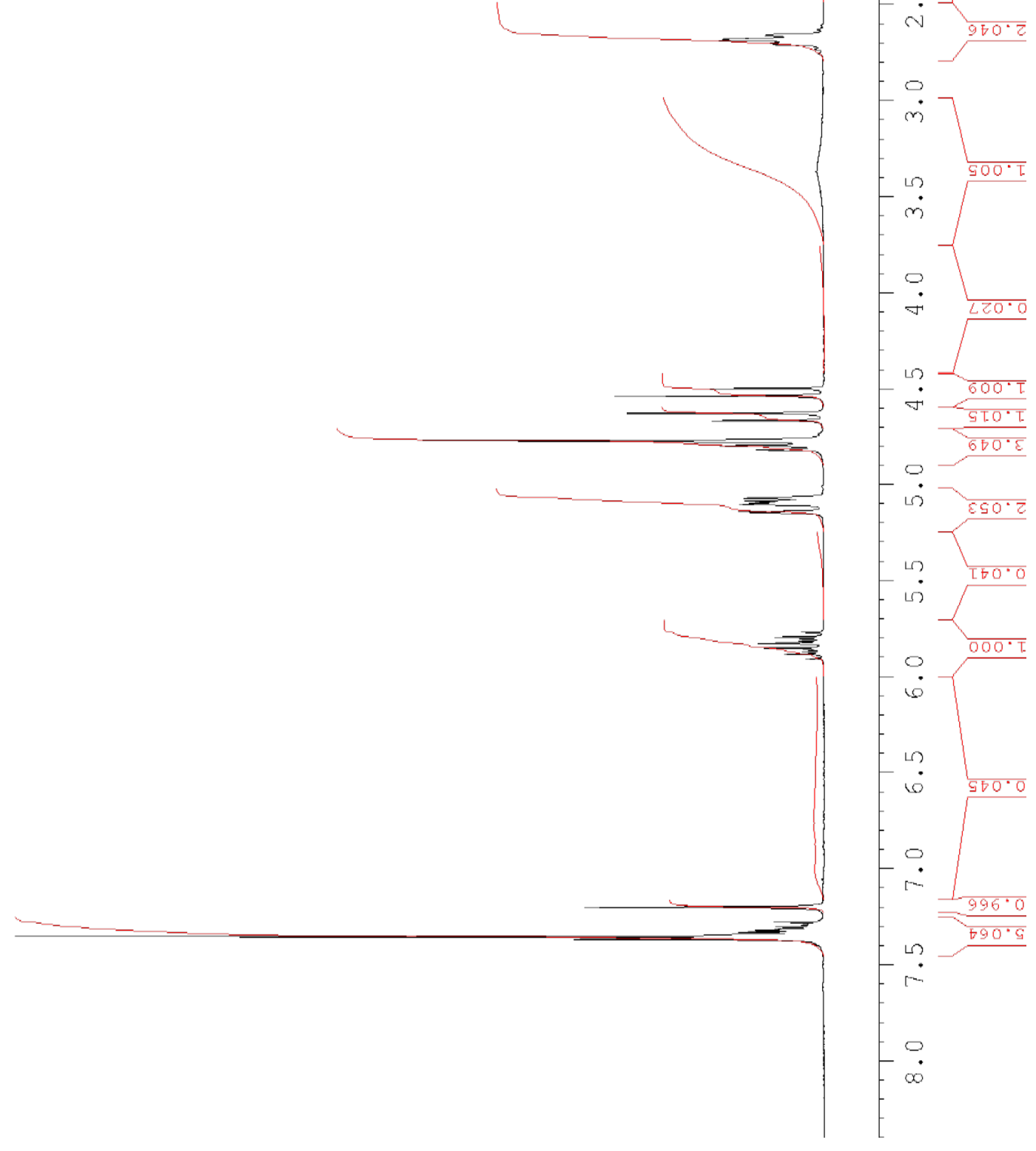




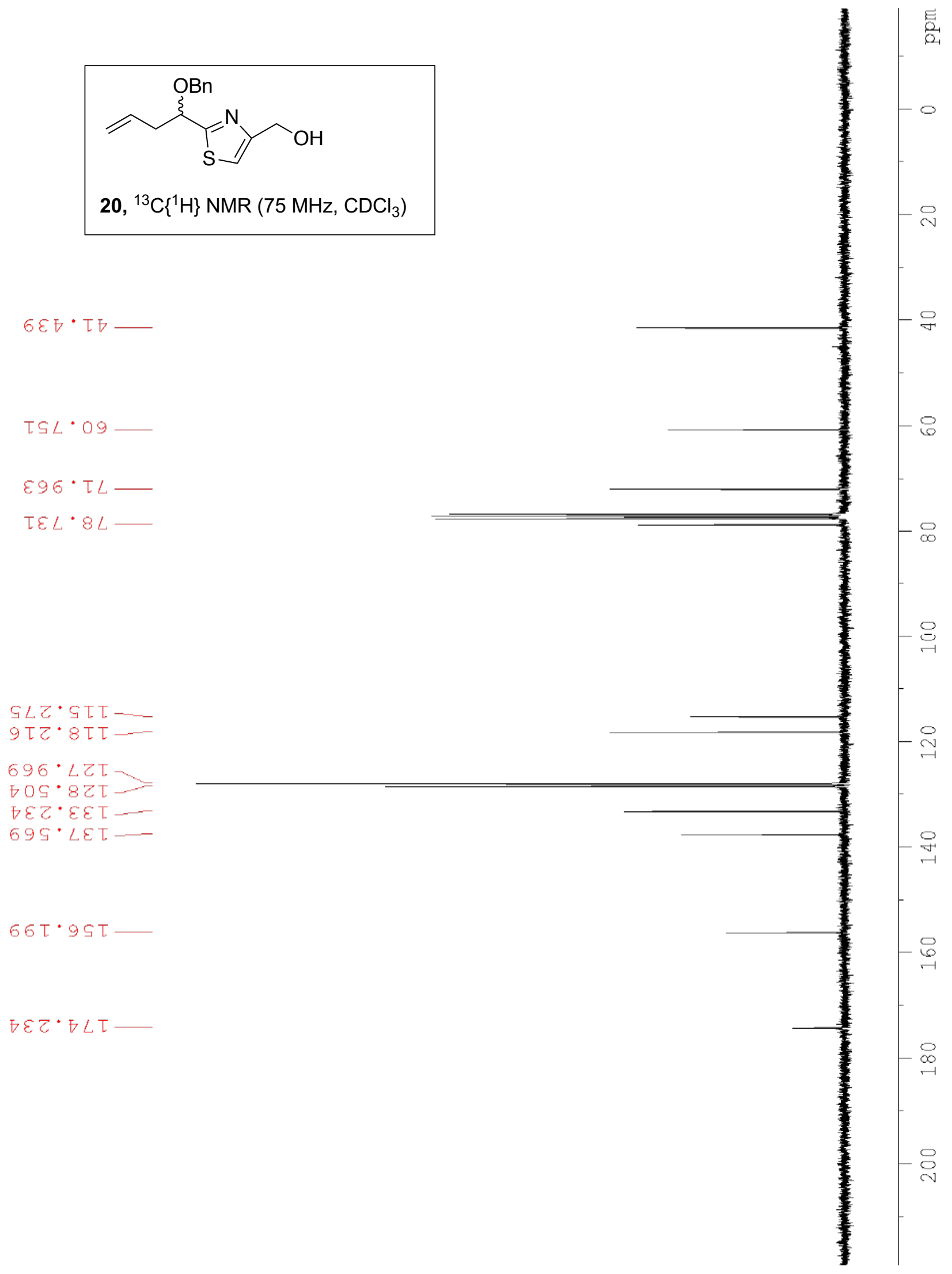




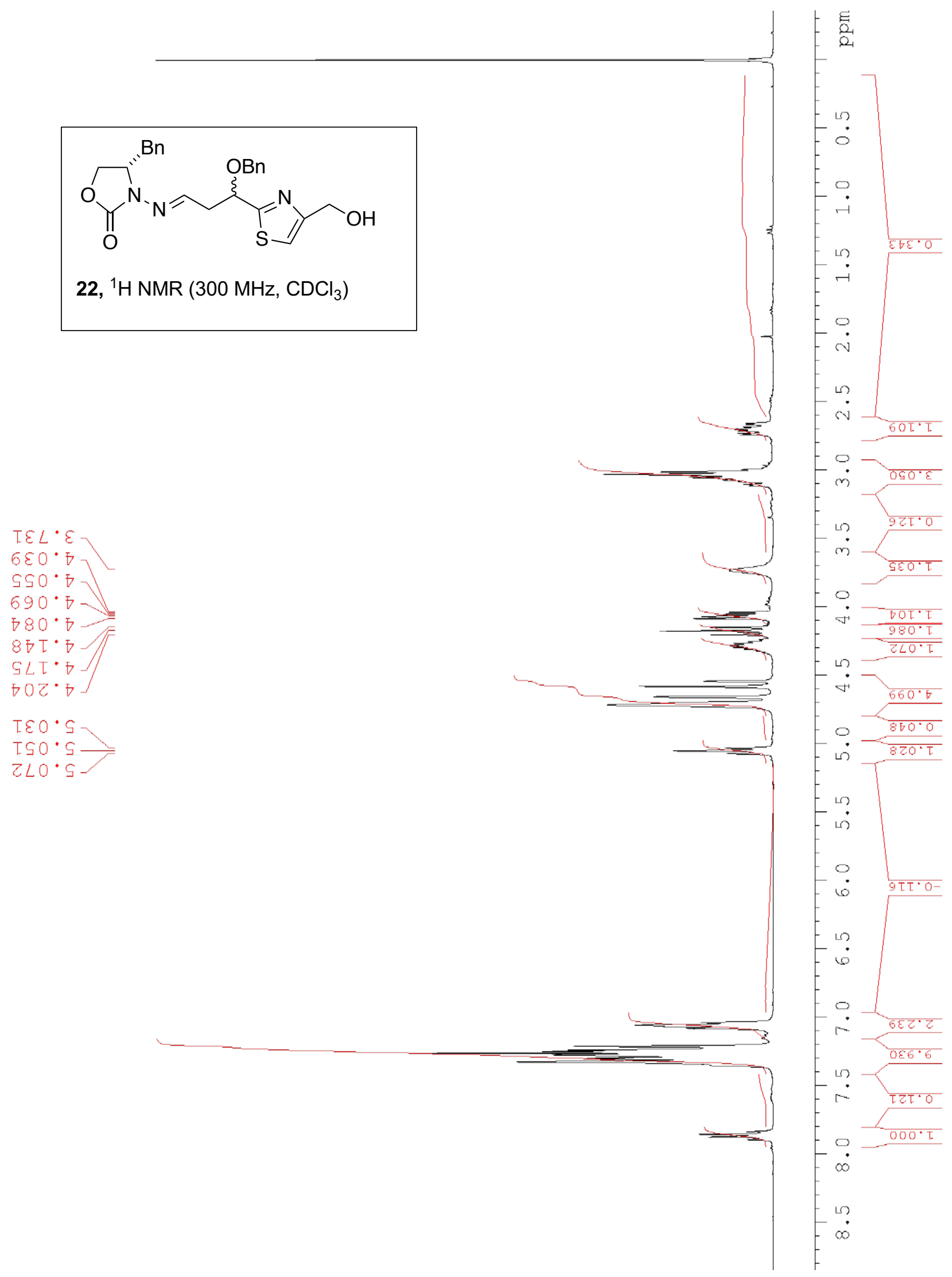




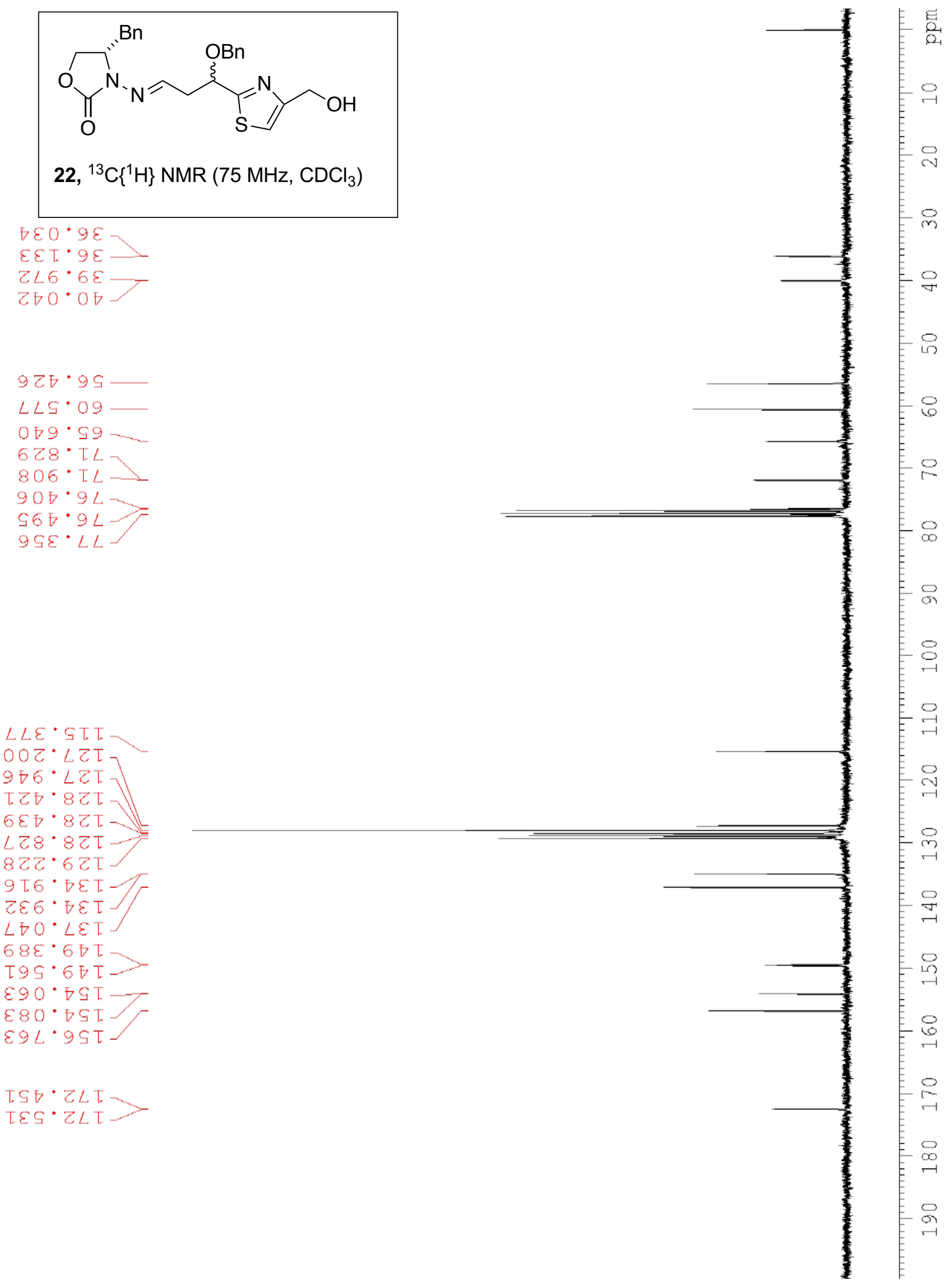




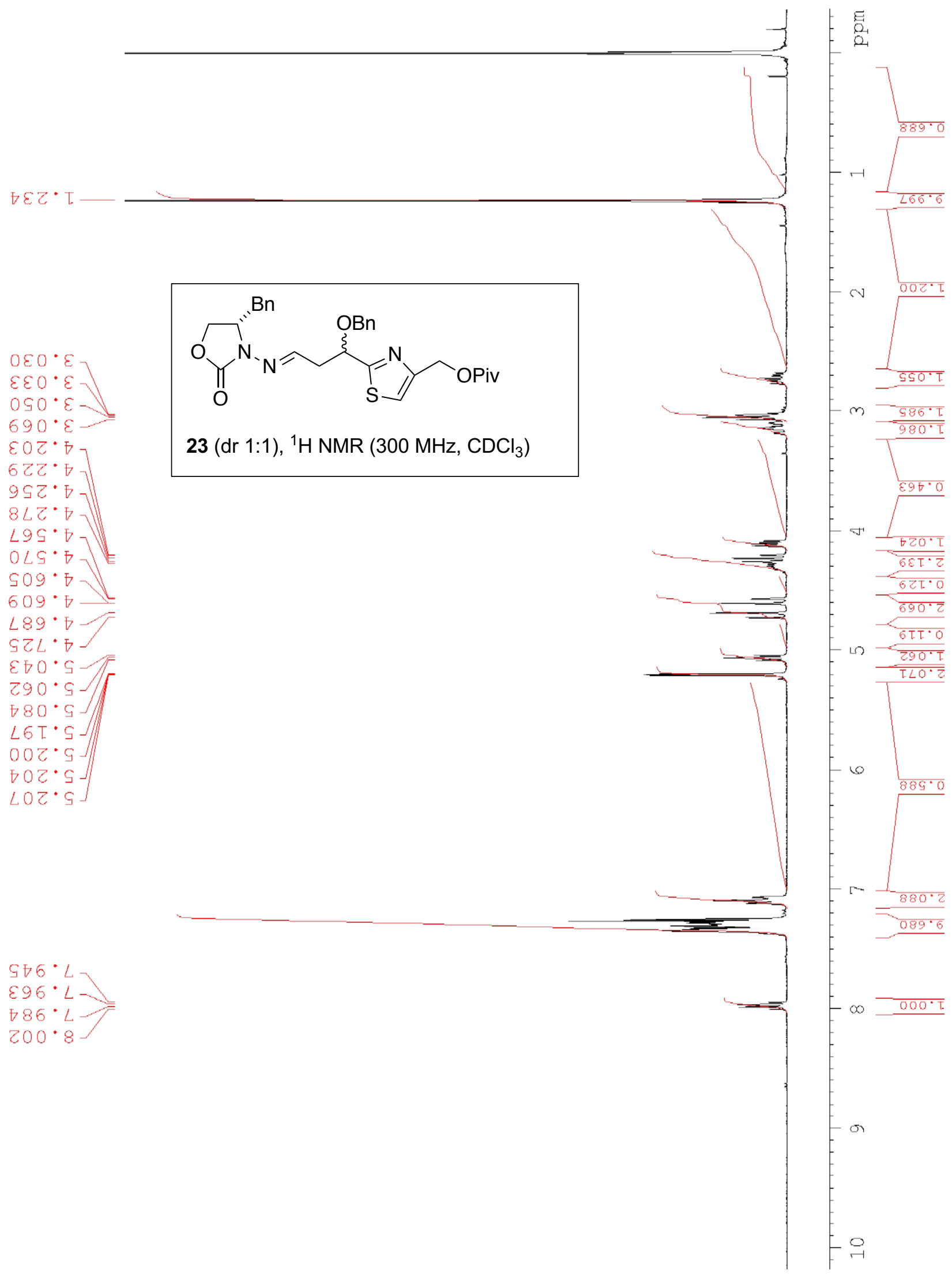



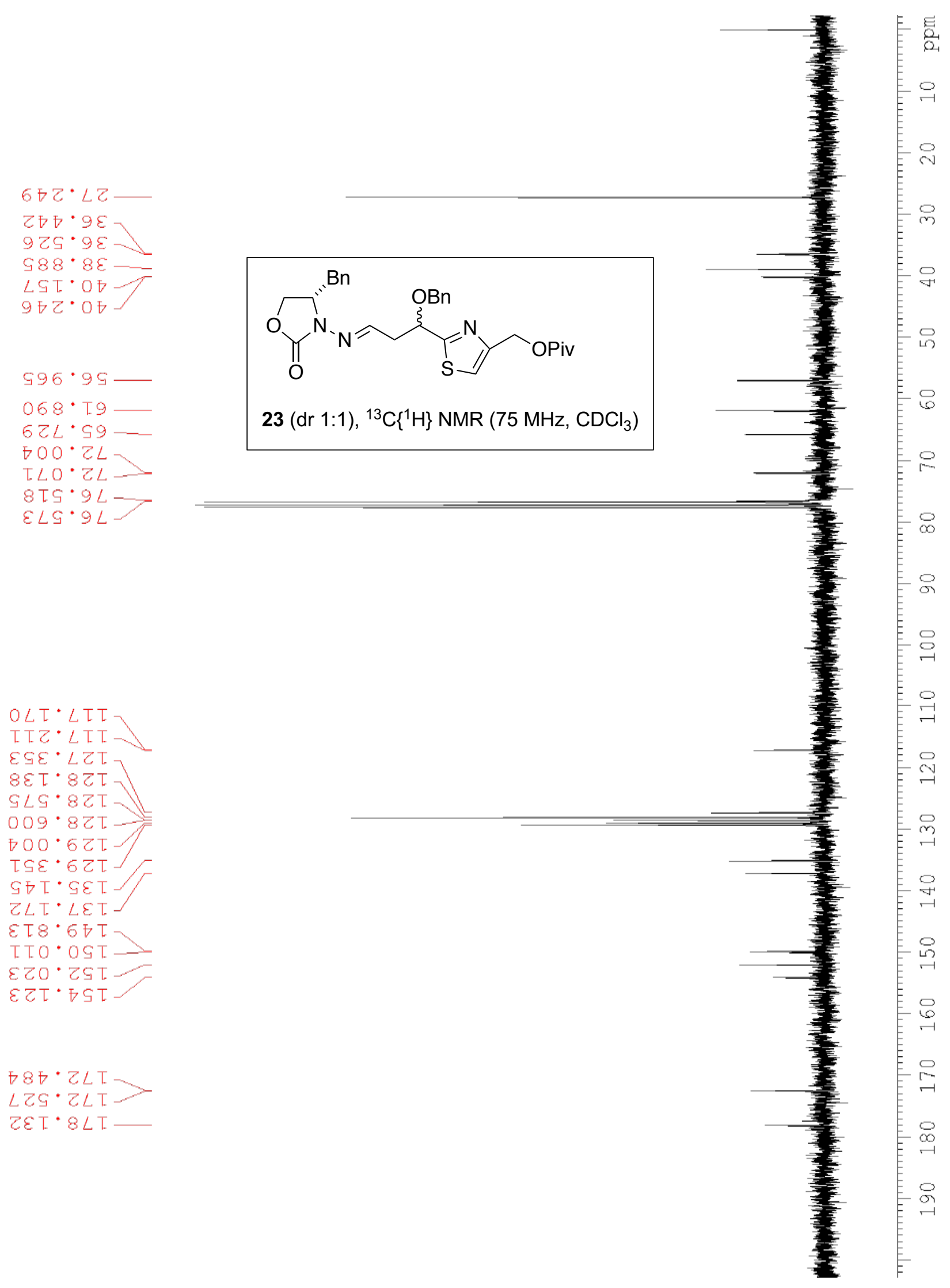


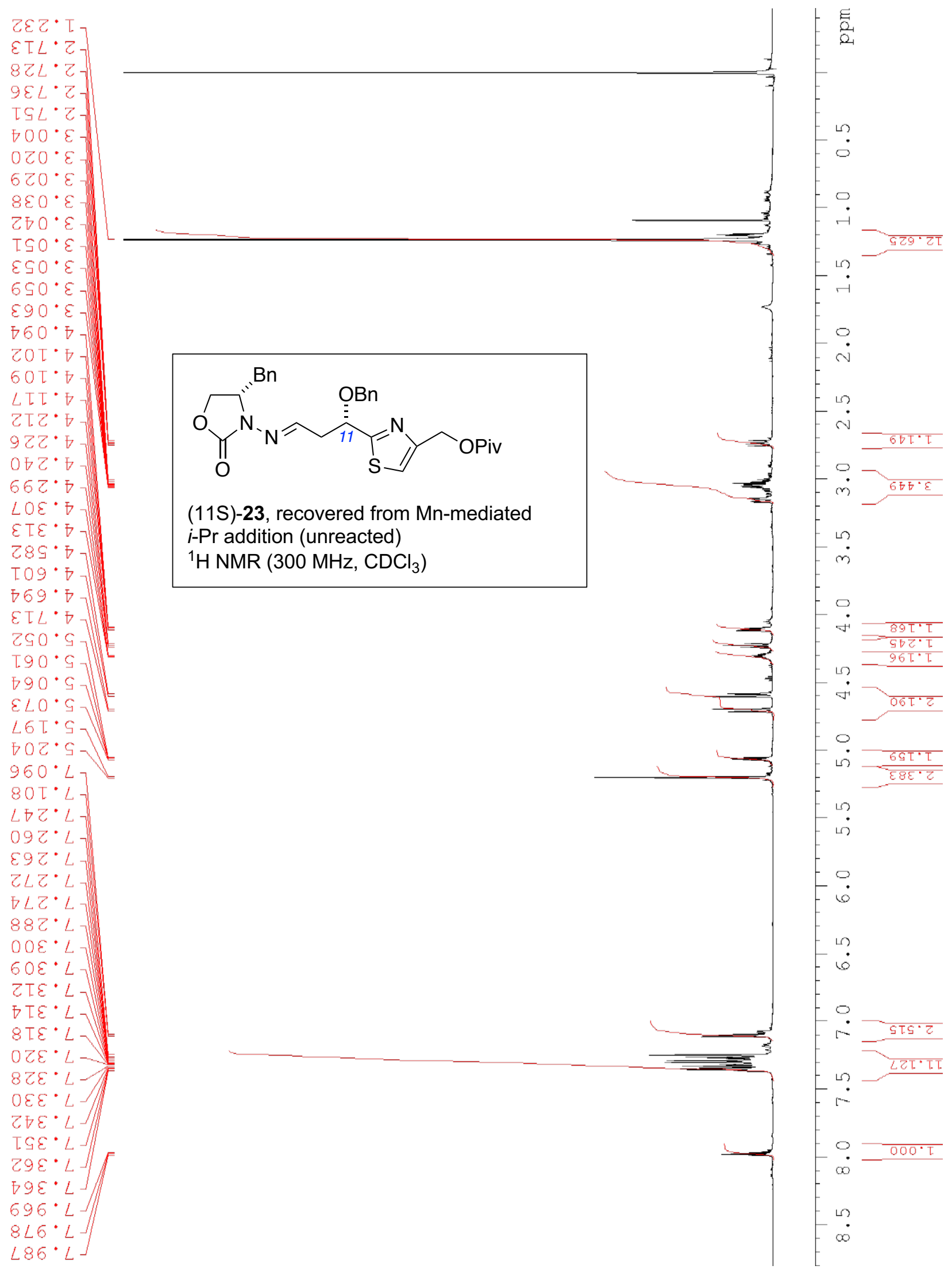




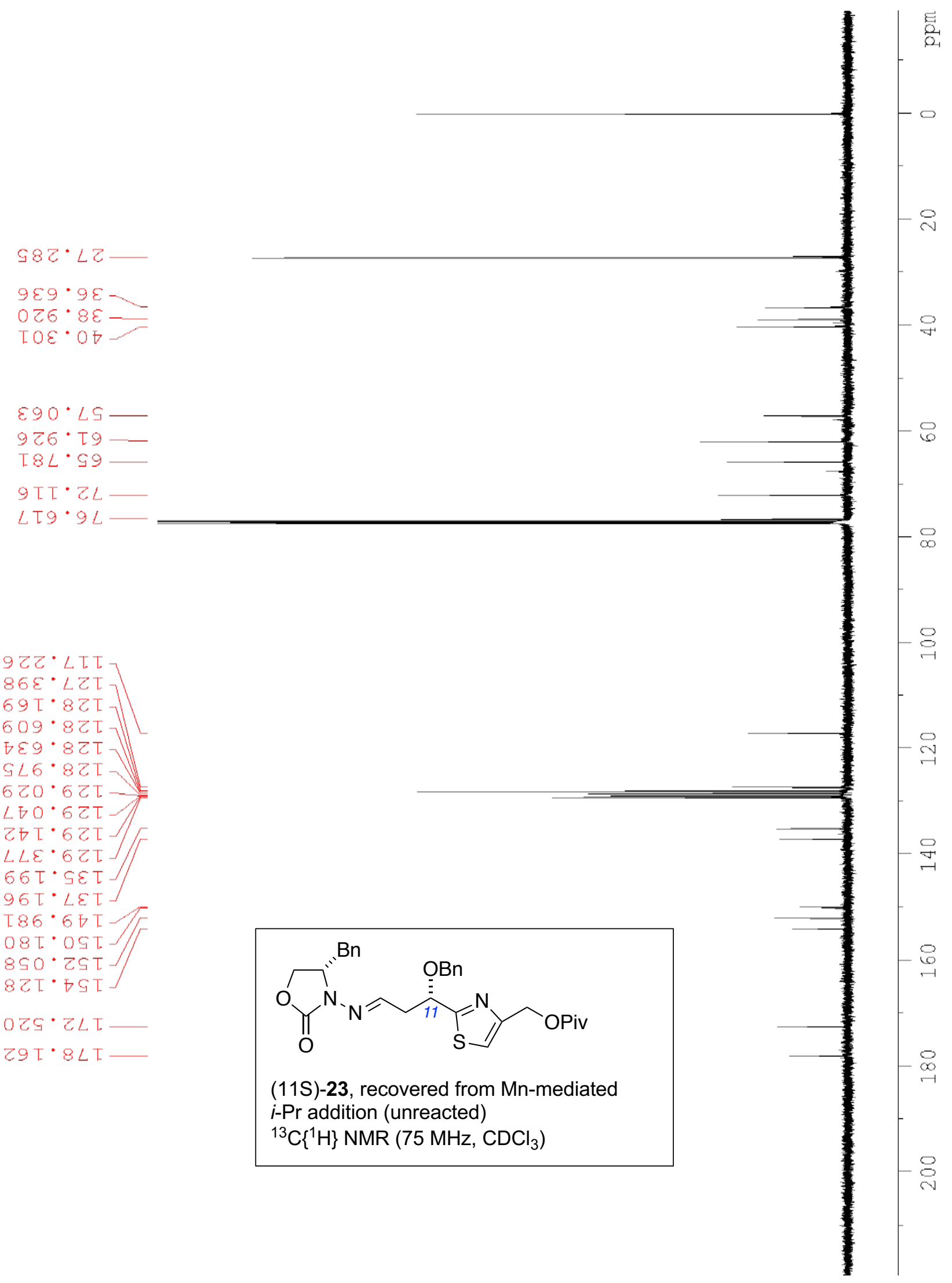




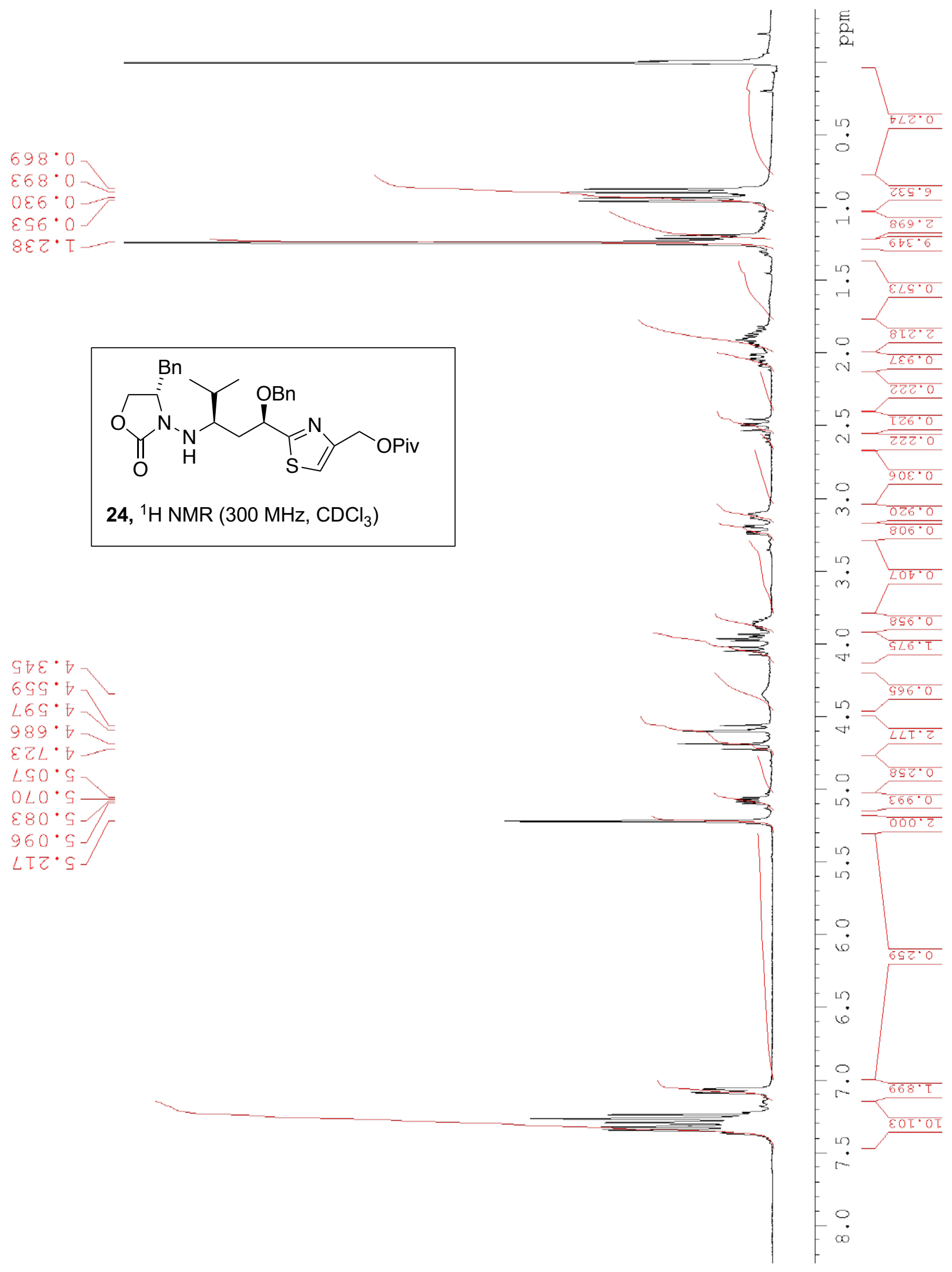



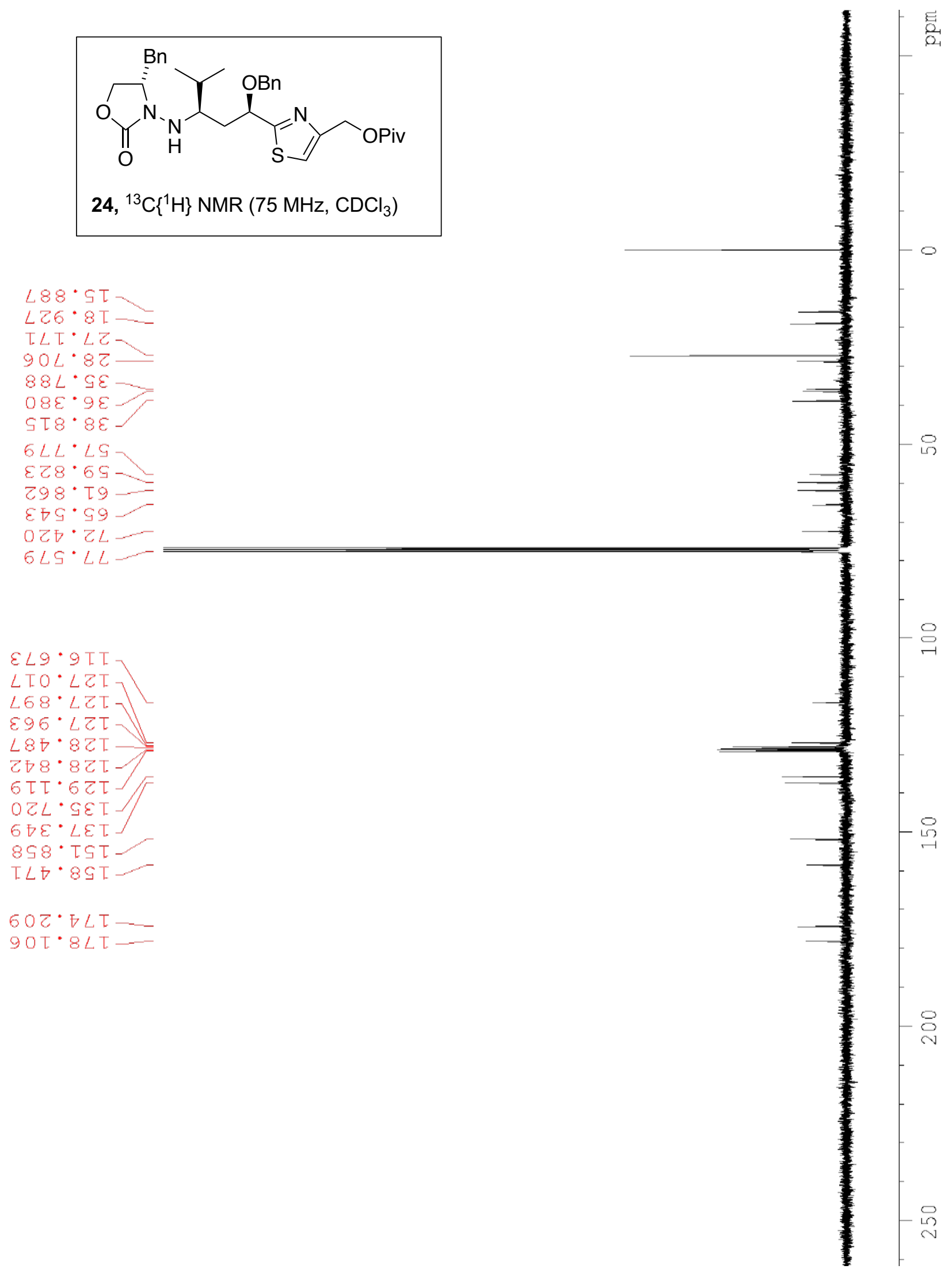

$90 \mathrm{~T} \cdot 8 \mathrm{~L}$ 


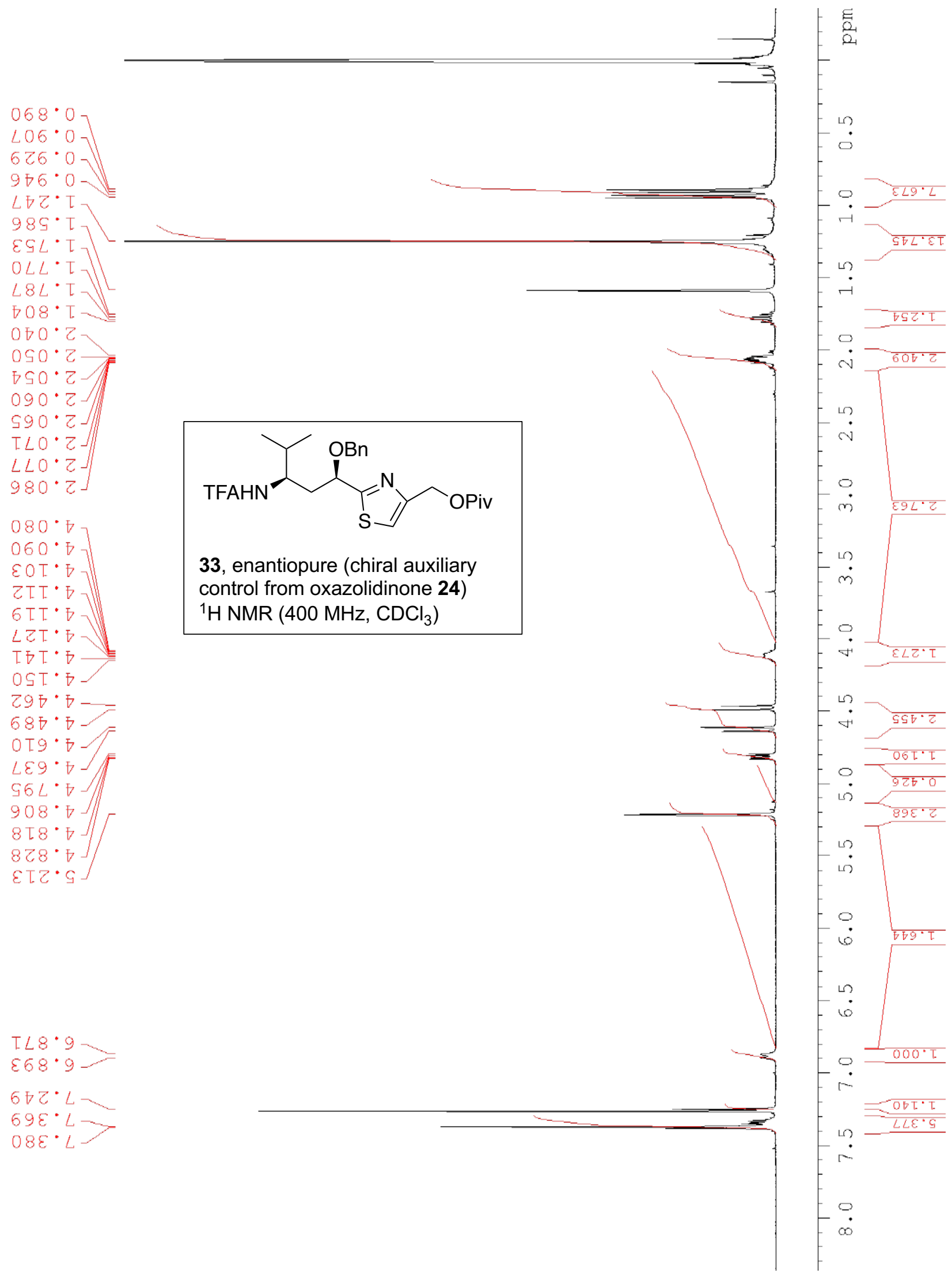




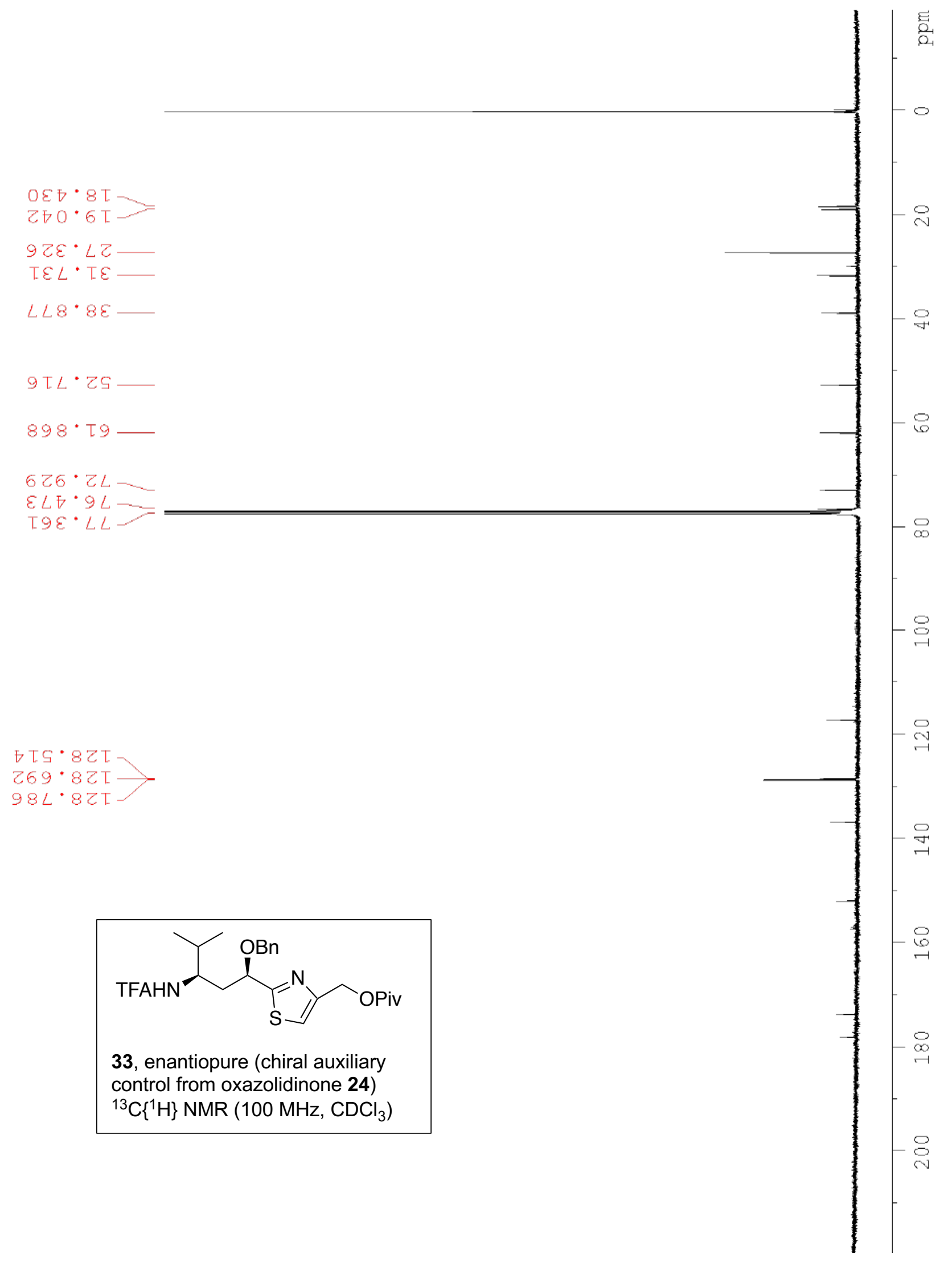




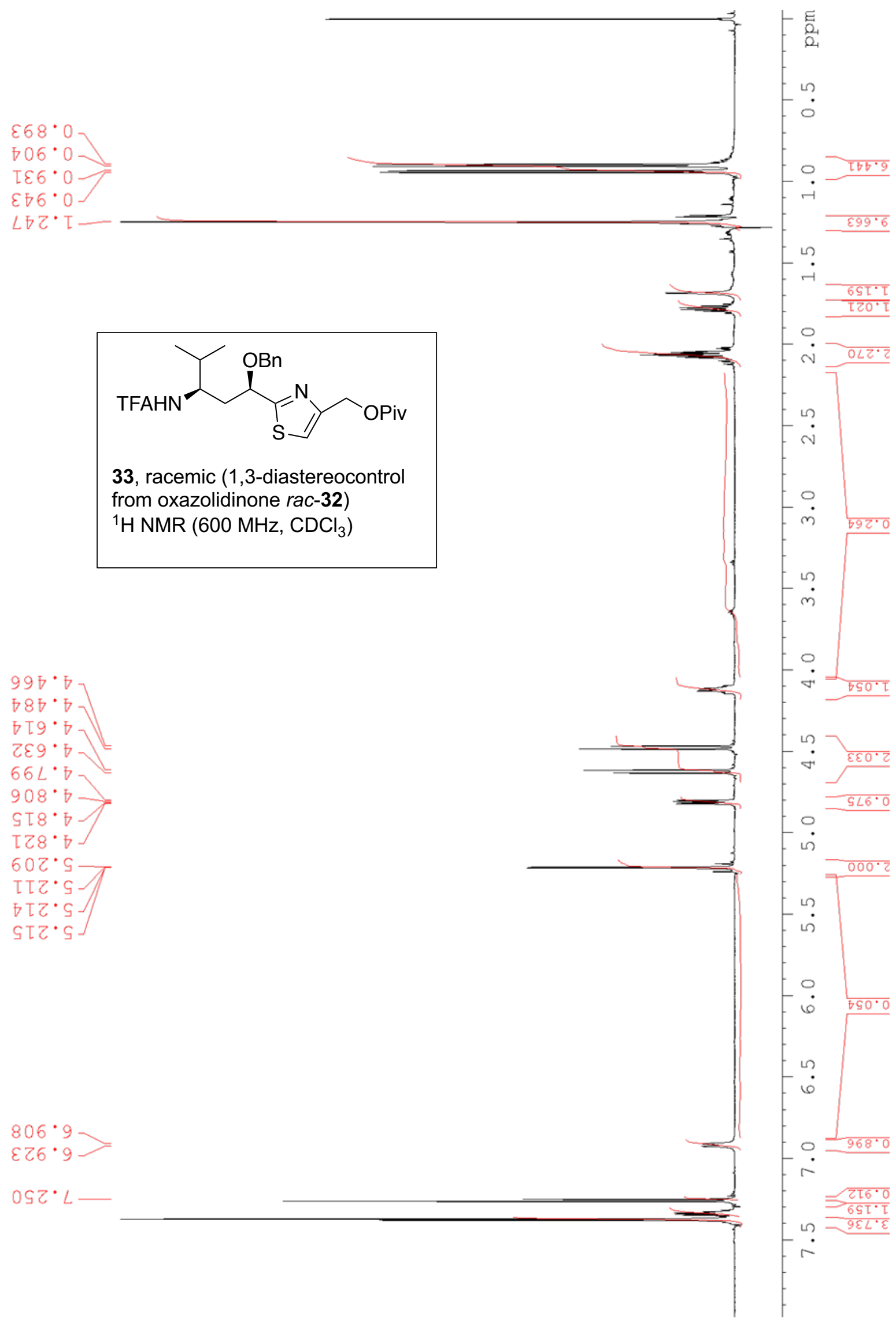




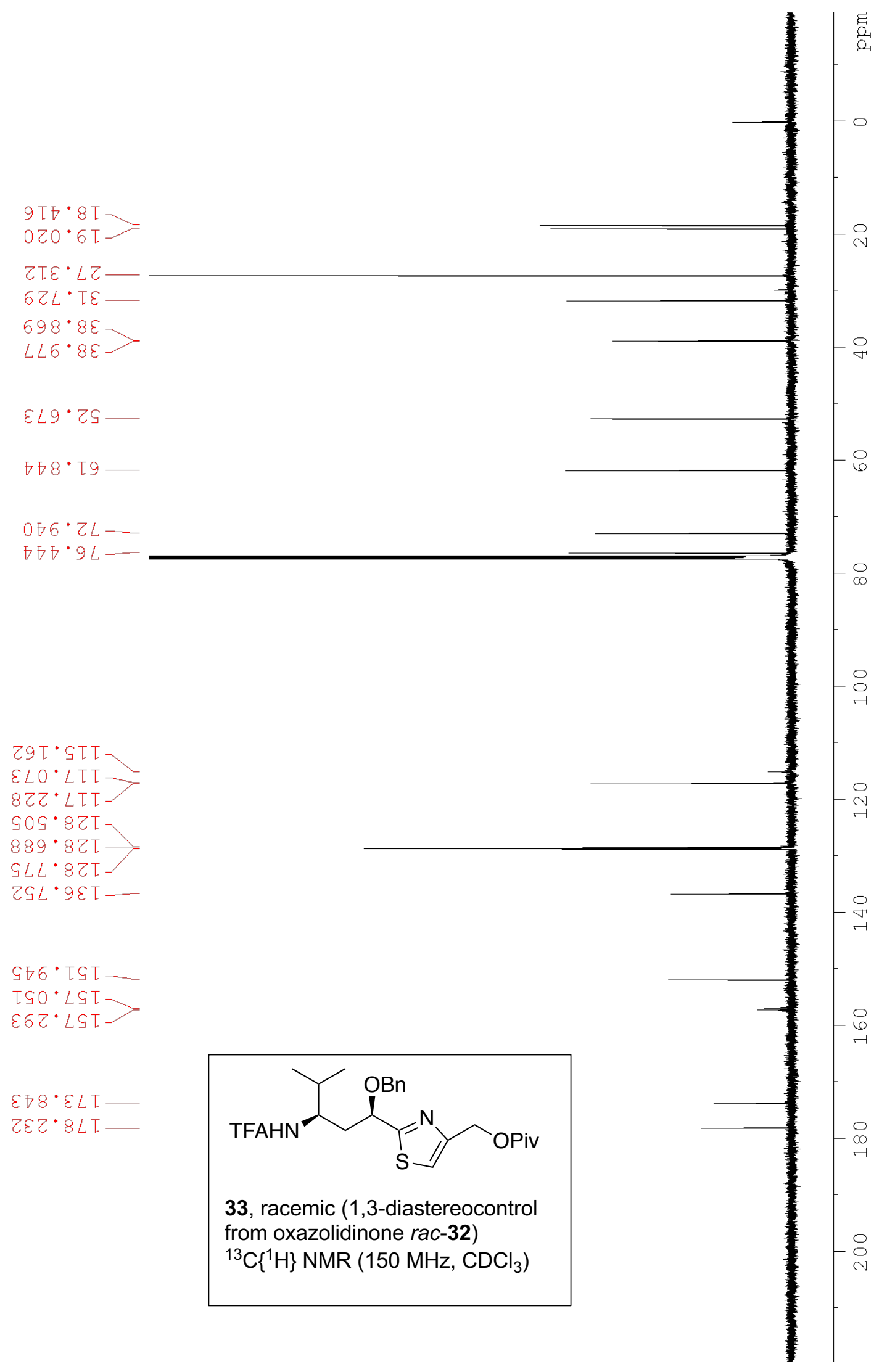




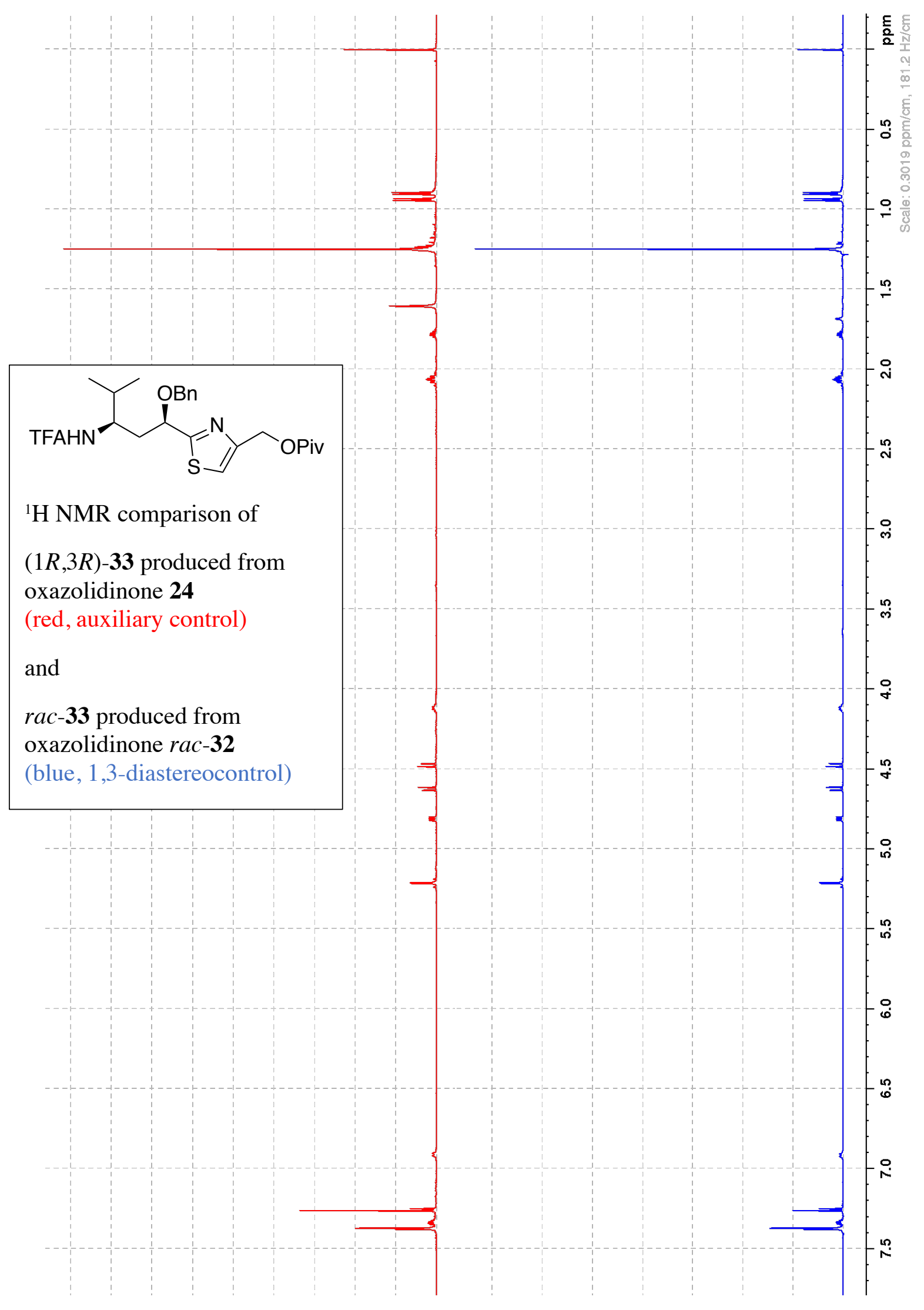




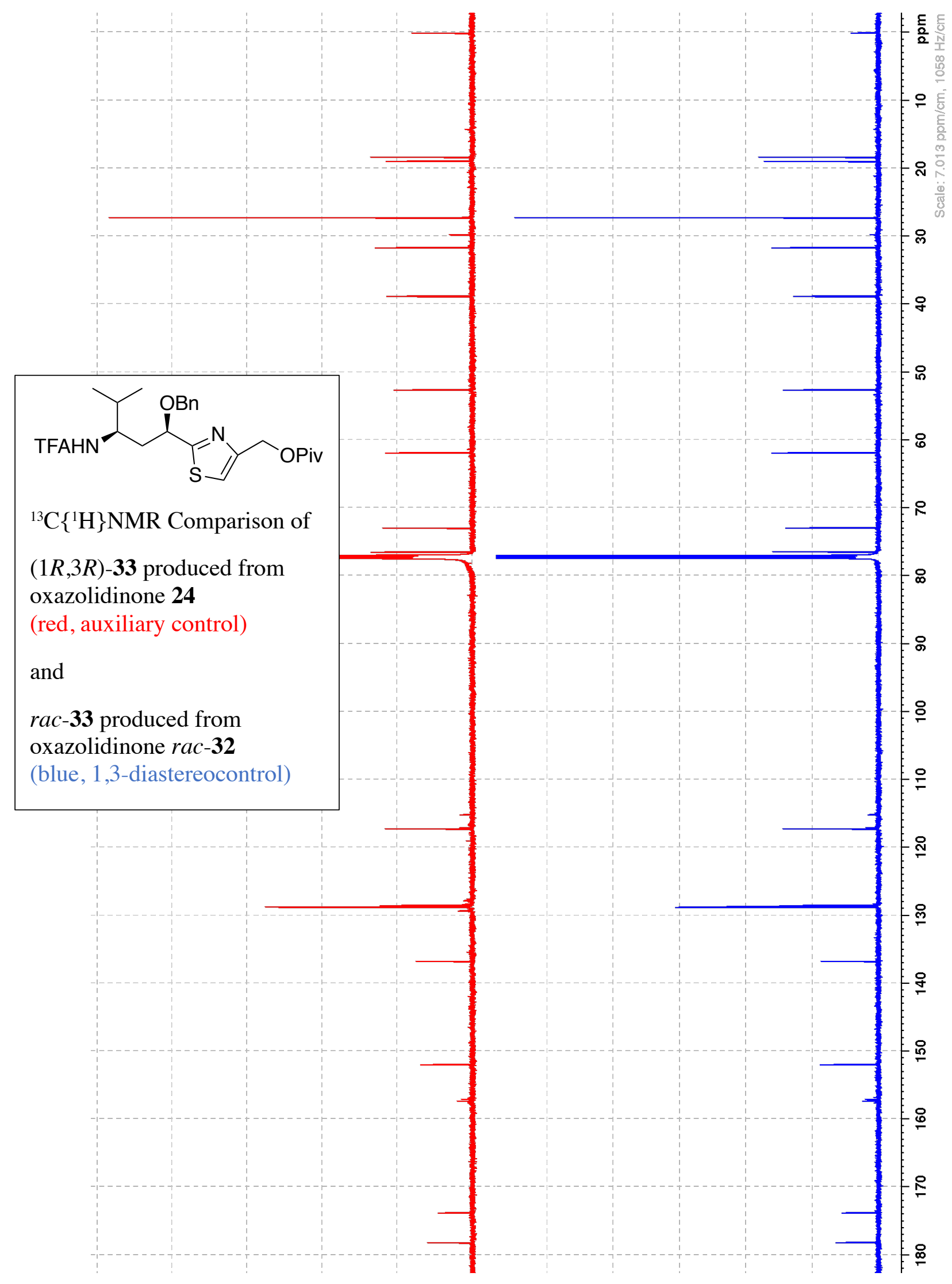




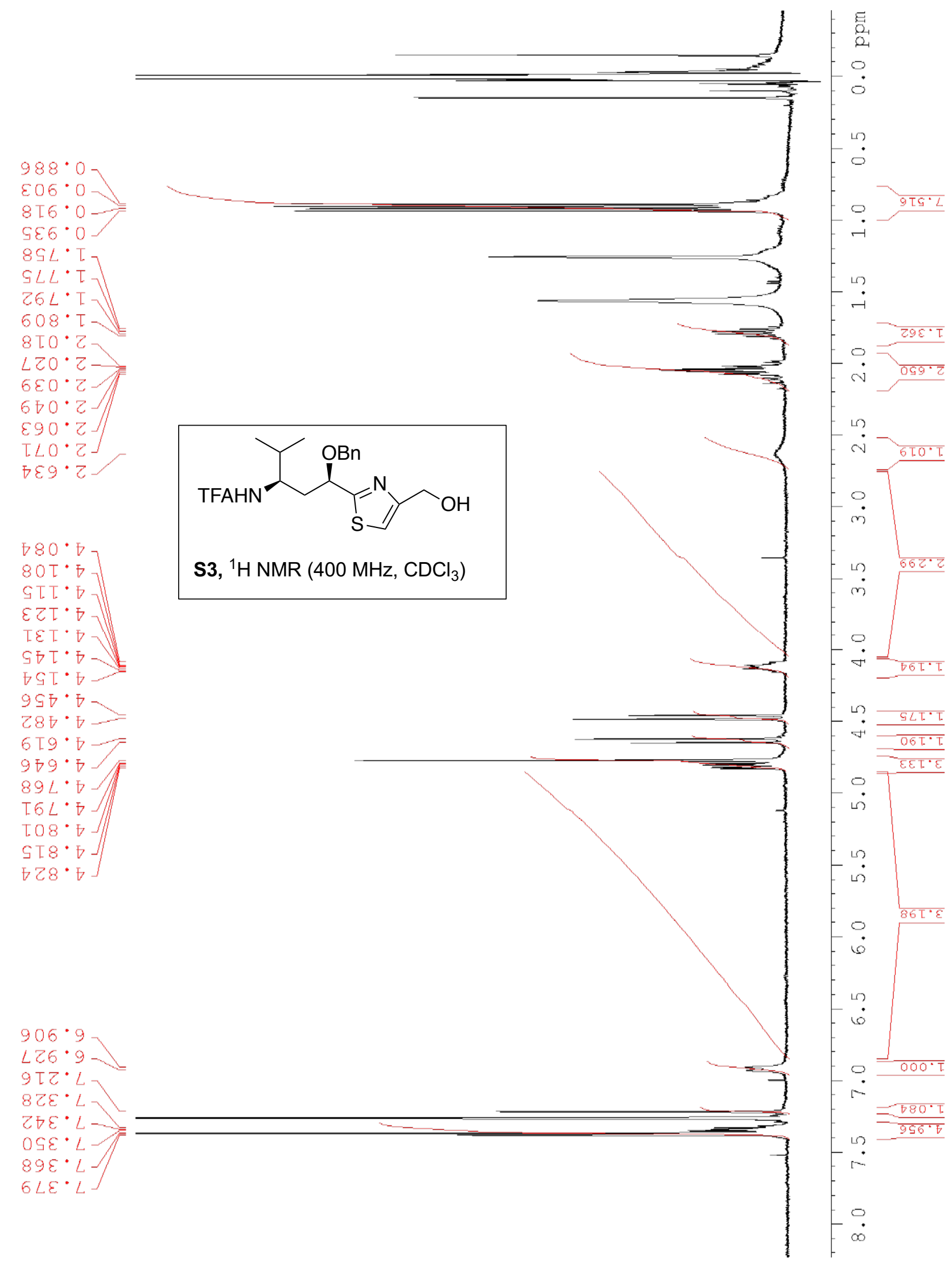


$\varepsilon 8 \varepsilon \cdot 8 T-$

$8 \angle 8 \cdot 8 T-2$

$8 \iota^{*} \tau \varepsilon$

$490 \cdot 68-$

$5 \angle S \cdot 25$

$298 \cdot 09$

$\overline{\varepsilon E T} \cdot \varepsilon t$

$297 \cdot 94$
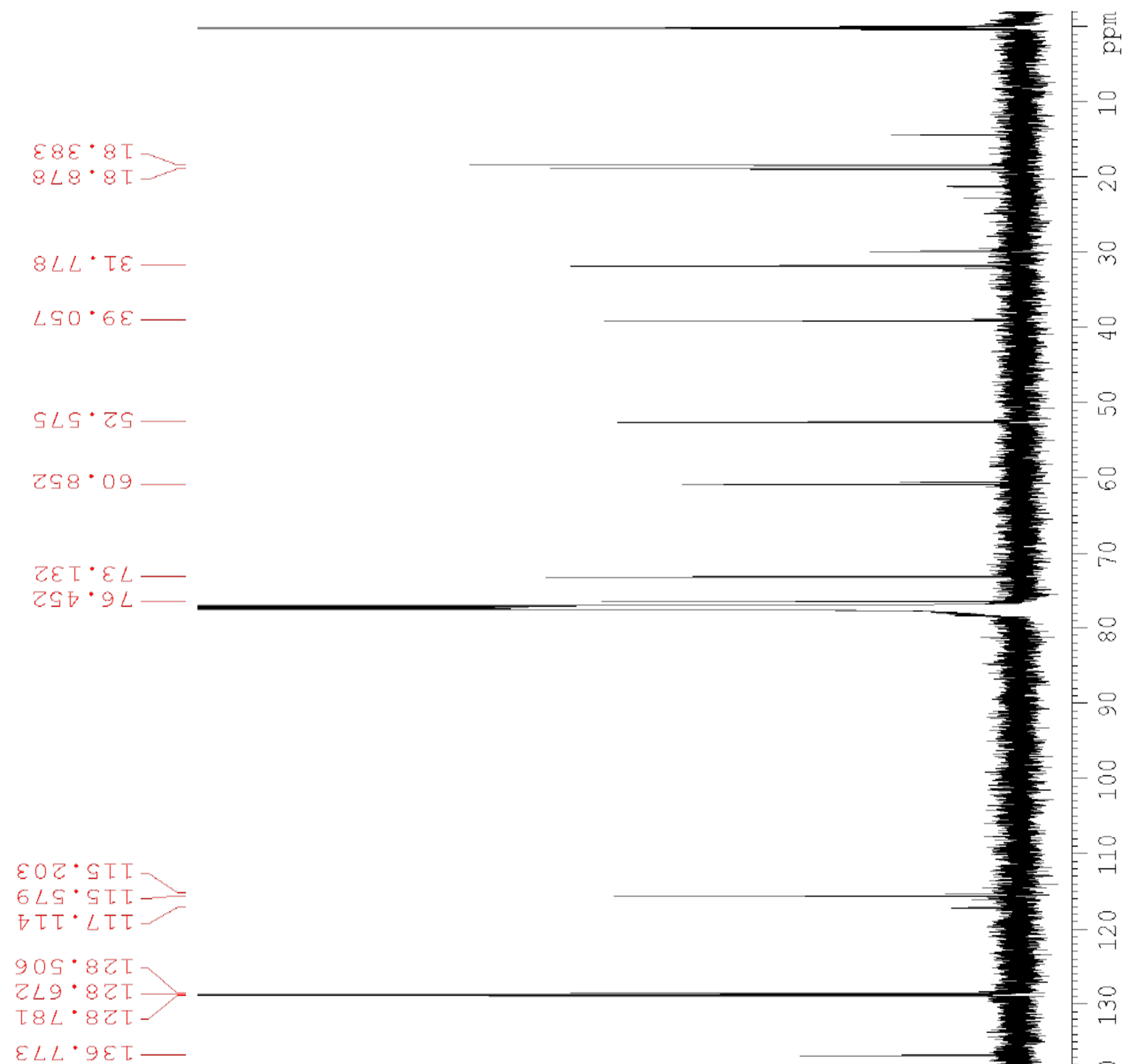

$6 s \varepsilon \cdot 9 \varsigma \tau$

$\tau \tau \cdot L S T-=$

$\varepsilon G \varepsilon \cdot \operatorname{LGT}$

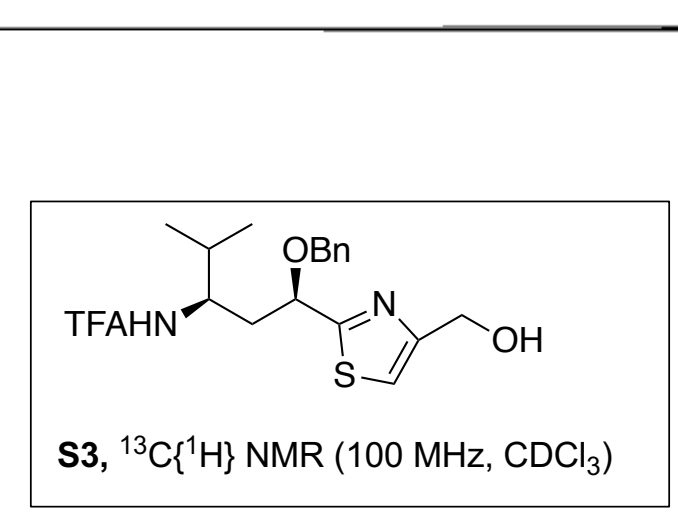

S3, ${ }^{13} \mathrm{C}\left\{{ }^{1} \mathrm{H}\right\} \operatorname{NMR}\left(100 \mathrm{MHz}, \mathrm{CDCl}_{3}\right)$

$99 S^{\circ} 7 L \mathrm{~T}$ 


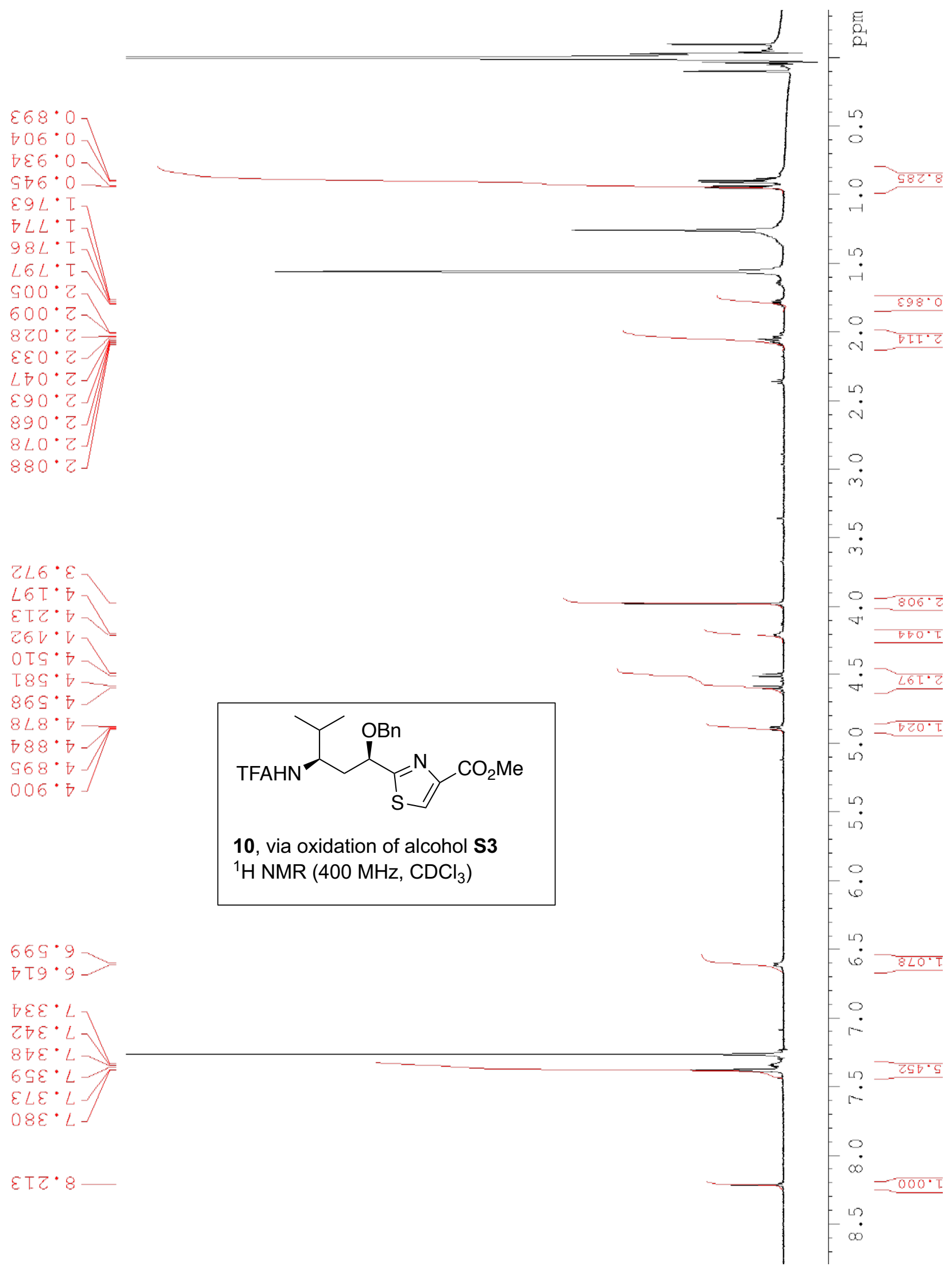


$08 T \cdot 8 T-2$

$9 \mathrm{~T} T \cdot 6 \mathrm{~T} \ldots$

$898 \cdot 62 \ldots$

$\varepsilon 96^{\circ} \mathrm{T \varepsilon} \ldots$

$6 \angle \varepsilon \cdot 6 \varepsilon-$

$\angle \mathrm{TZ} \cdot 29-\ldots$

$29 L \cdot 29=$

$727 \cdot \varepsilon$
$867 \cdot 9$

$98 \varepsilon \cdot 8 \mathrm{~T}$

$909 \cdot 8 \mathrm{Z}$

$0 \angle L \cdot 8 Z$

GT.8.8ZT.

$699^{\circ} \cdot 98 \tau$

$8 \nabla 0 \cdot L \nabla T$<smiles>CC(=O)c1csc([C@@H](C[C@H](NC(F)F)C(C)C)Oc2ccccc2)n1</smiles>

10 , via oxidation of alcohol $\mathrm{S} 3$ ${ }^{13} \mathrm{C}\left\{{ }^{1} \mathrm{H}\right\} \mathrm{NMR}\left(100 \mathrm{MHz}, \mathrm{CDCl}_{3}\right)$

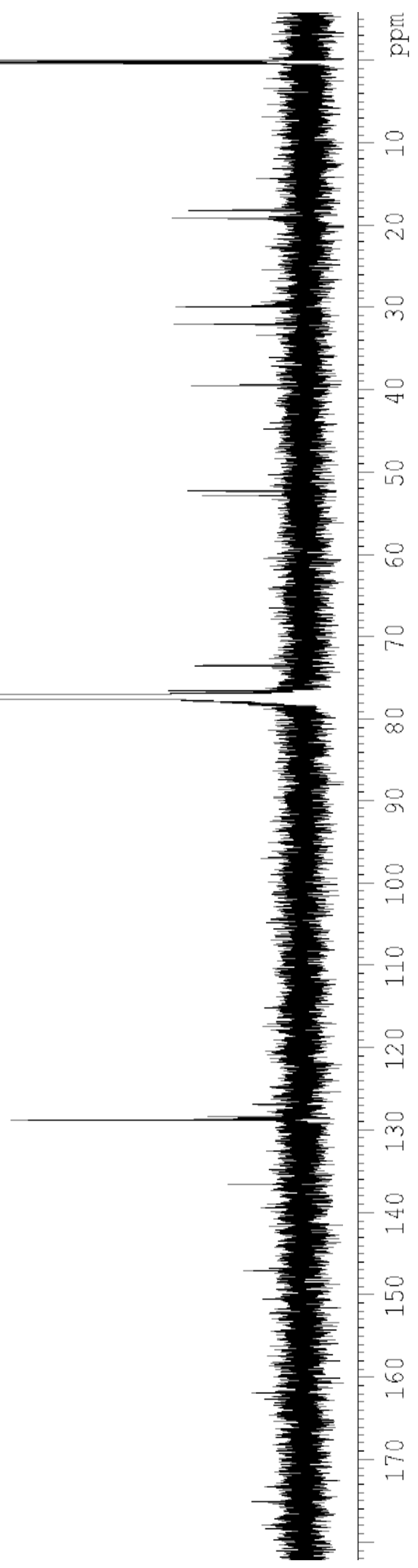




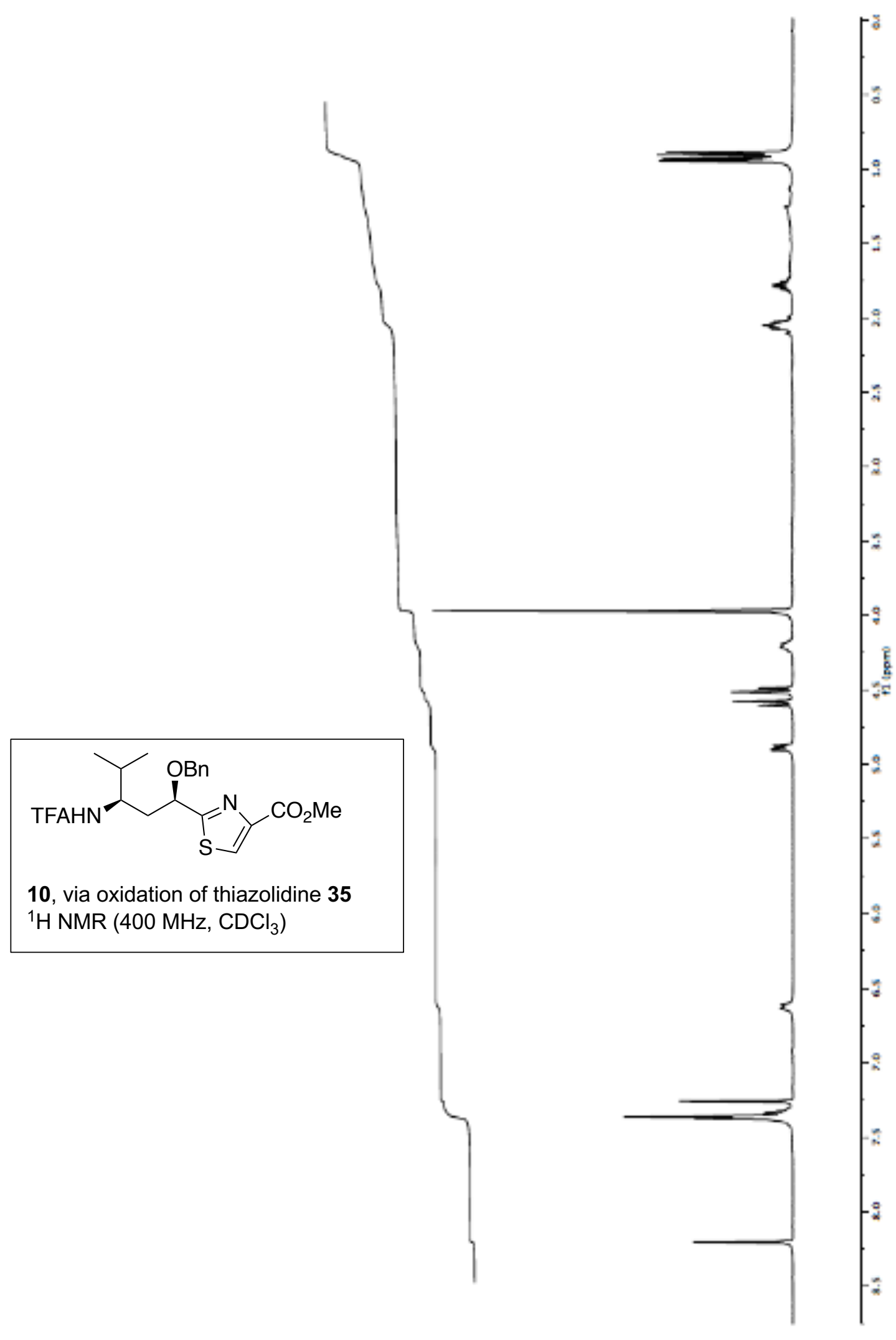




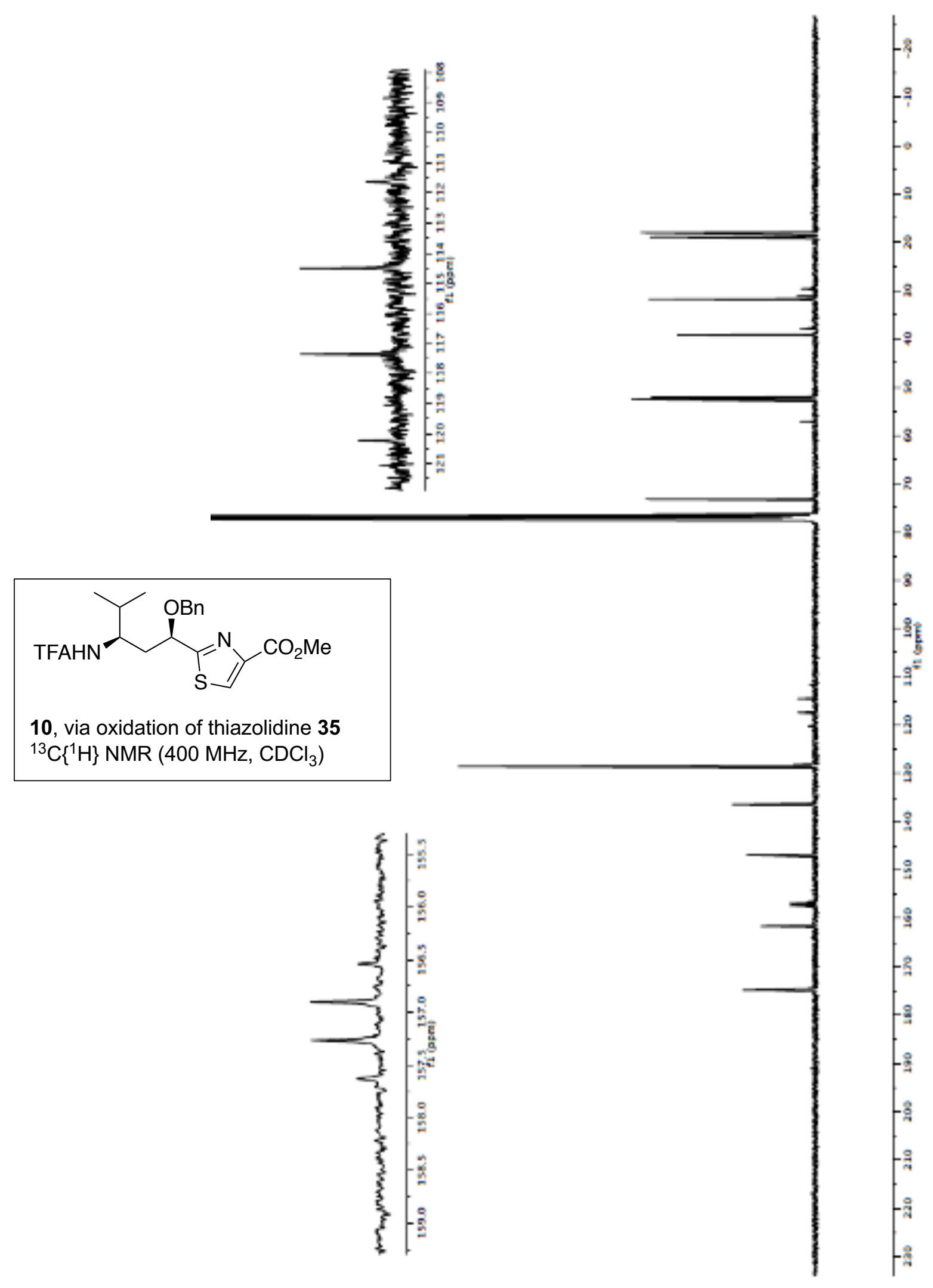



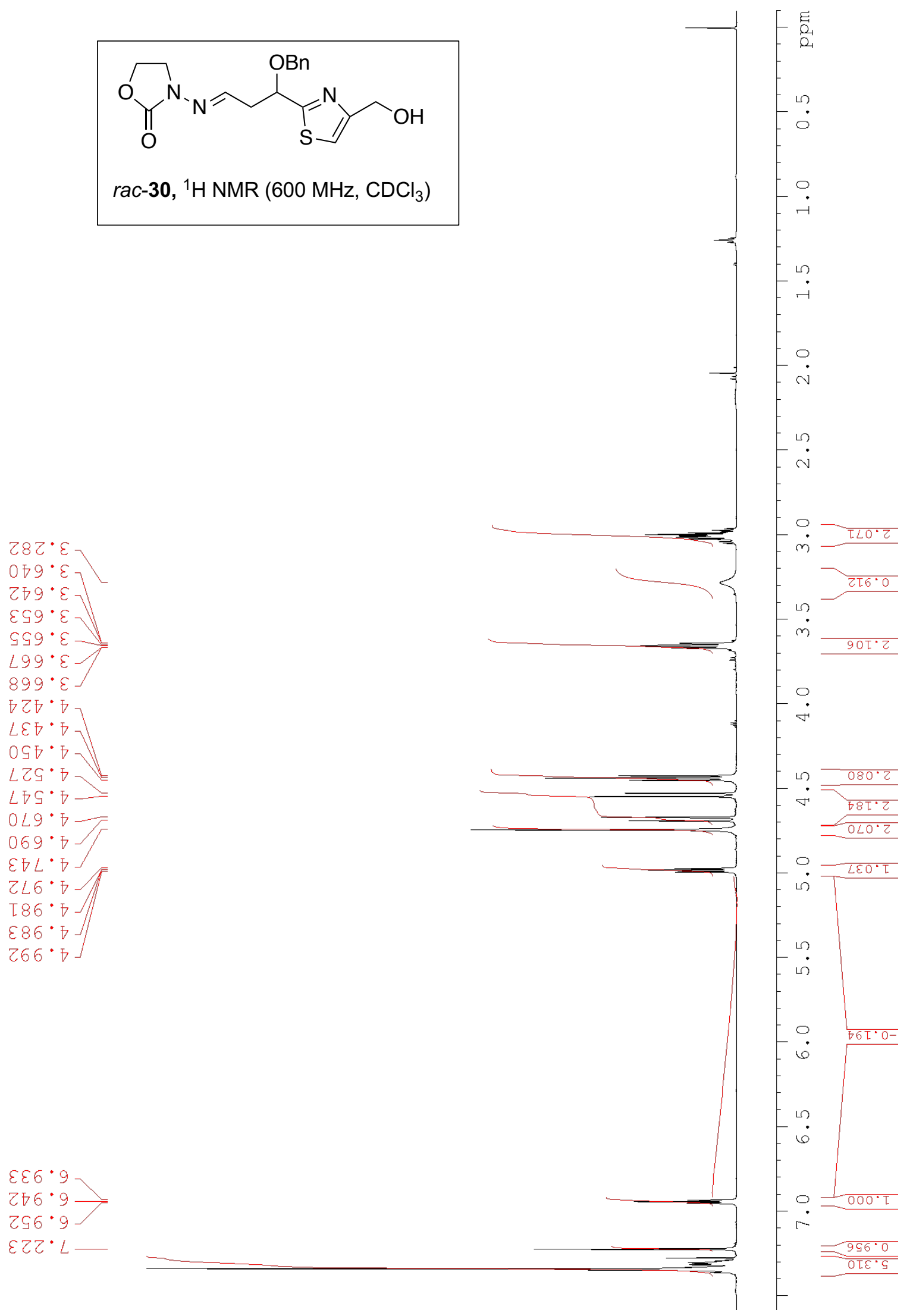

$\varepsilon \varepsilon 6 \cdot 9$

乙७ $6^{\circ} 9$

$296 \cdot 9$

$\varepsilon 乙{ }^{*} L$

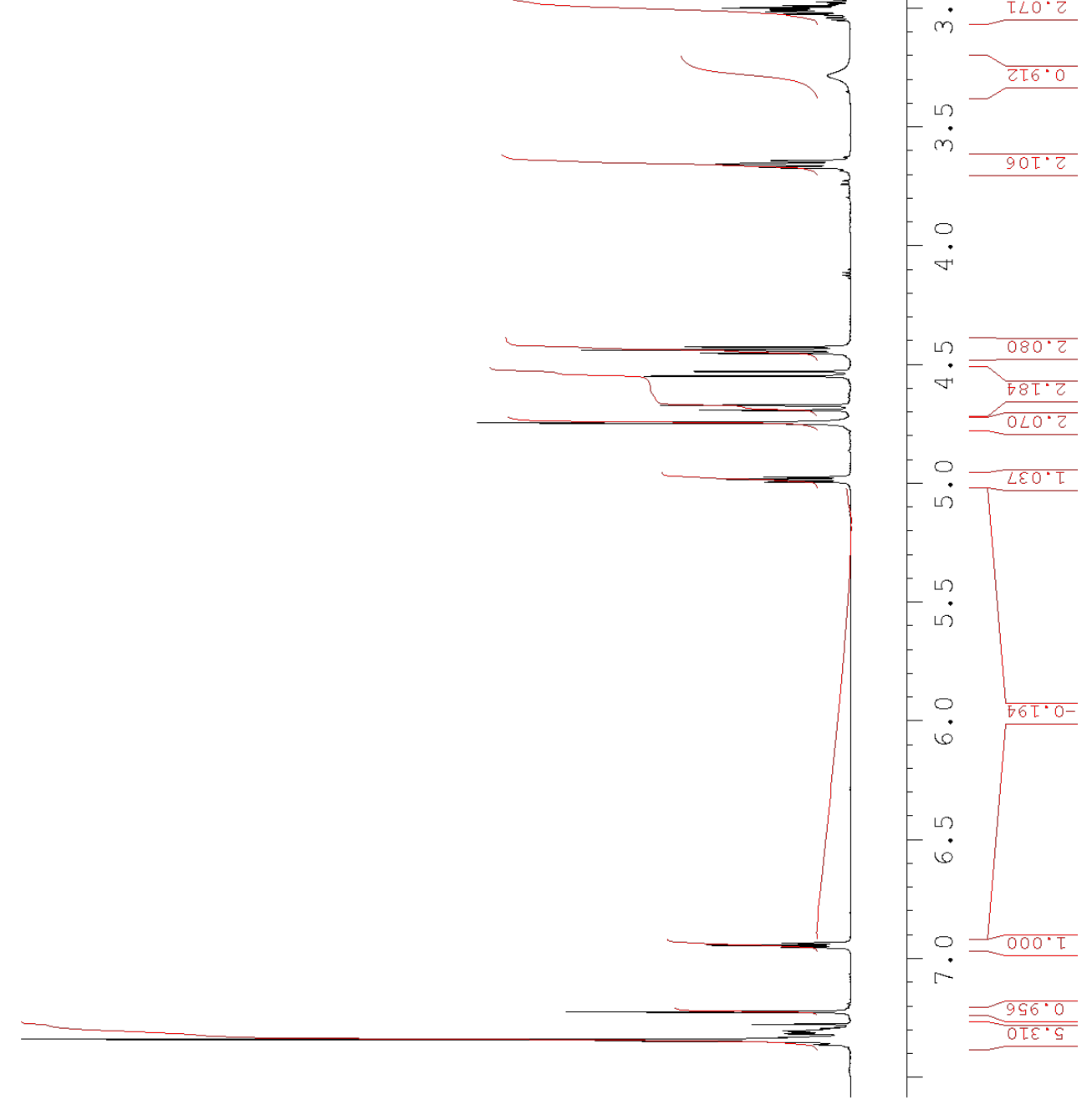



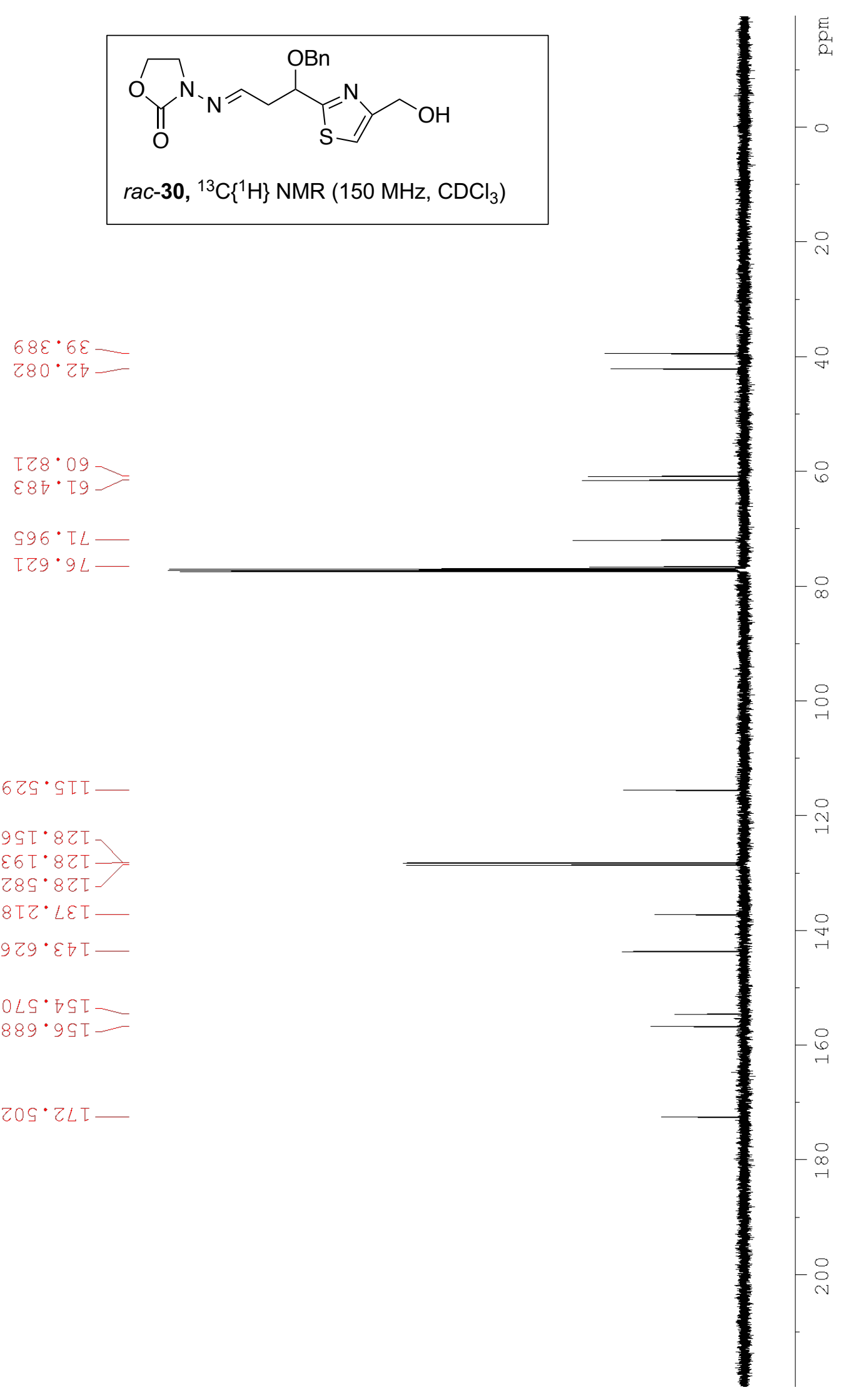


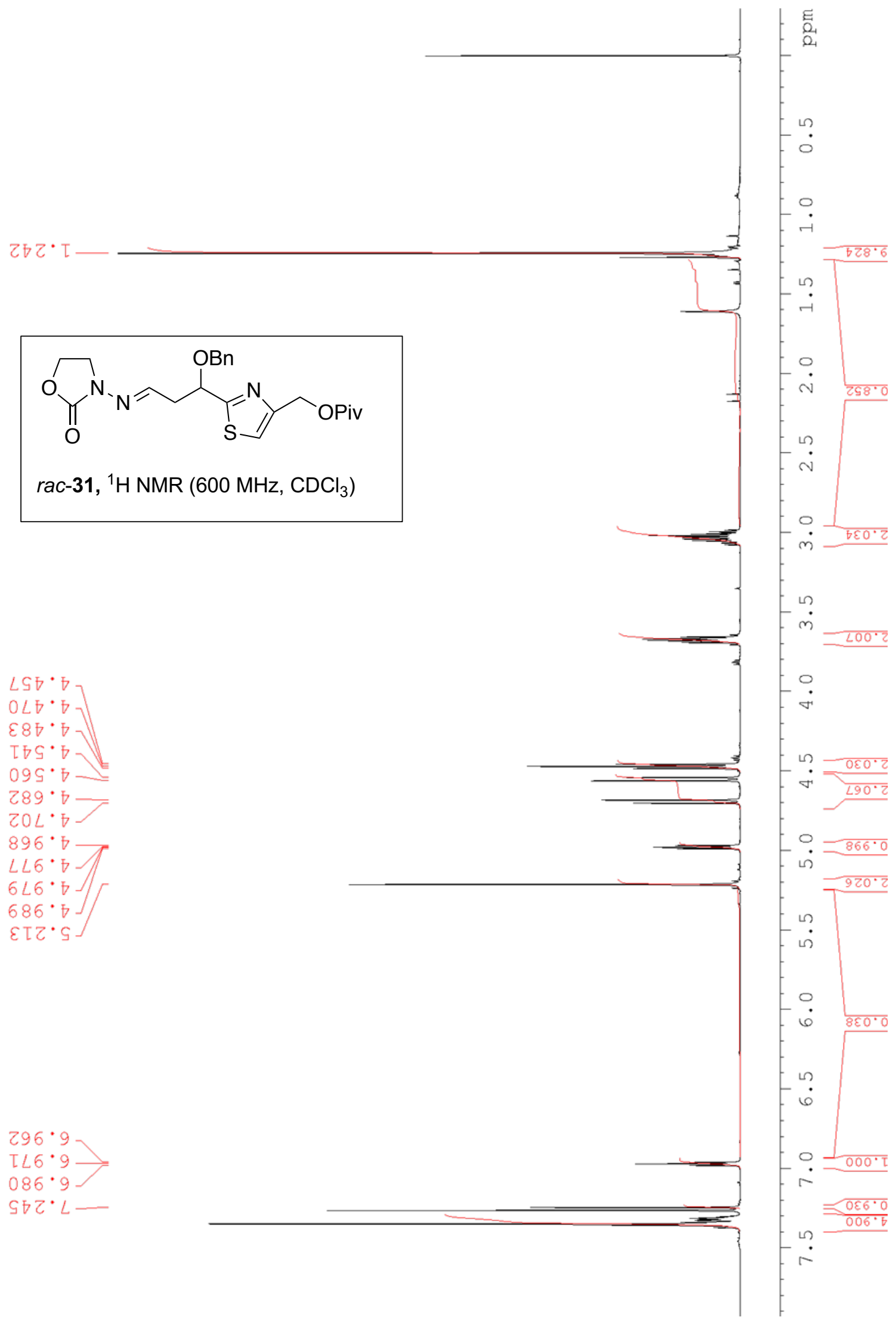




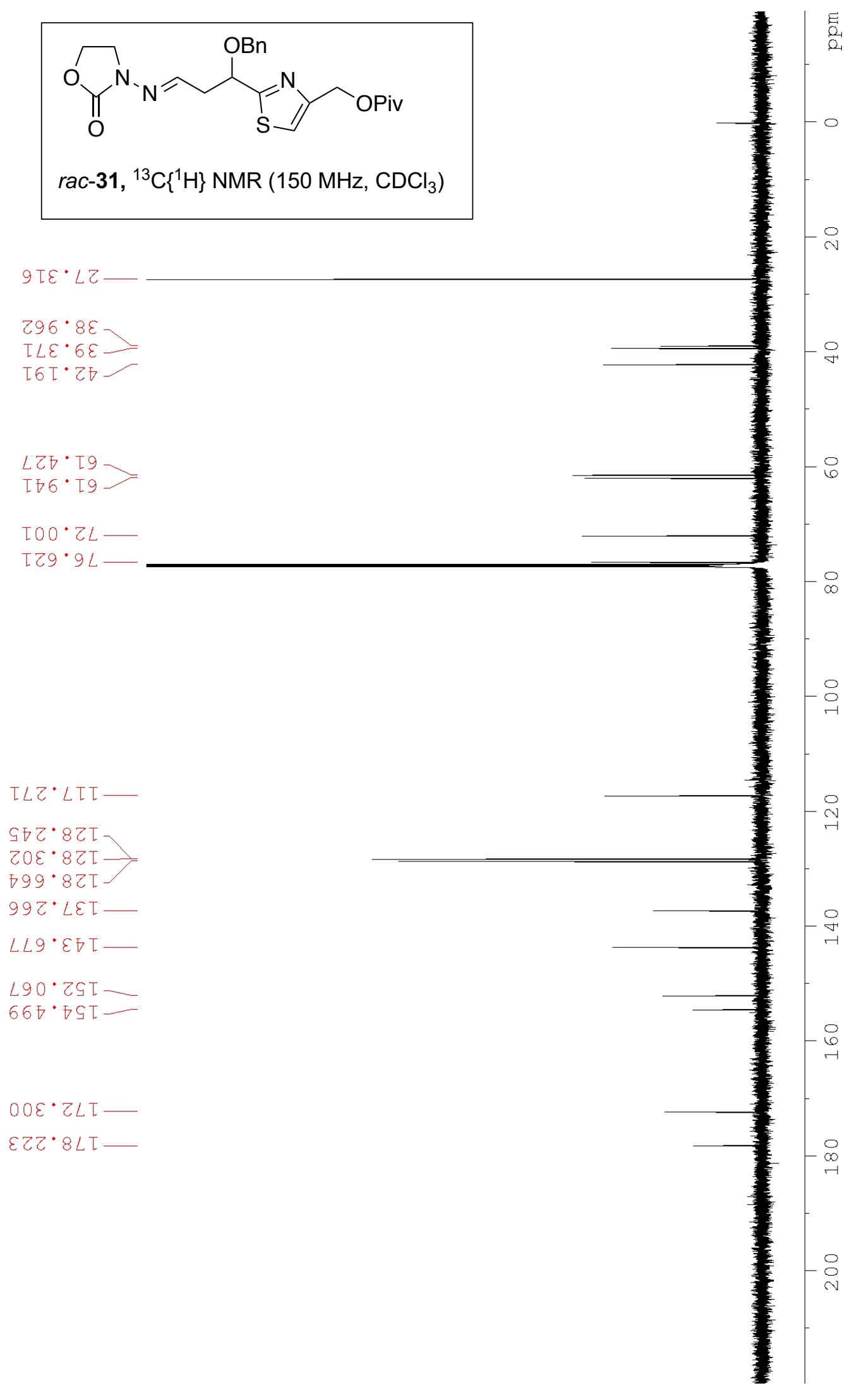




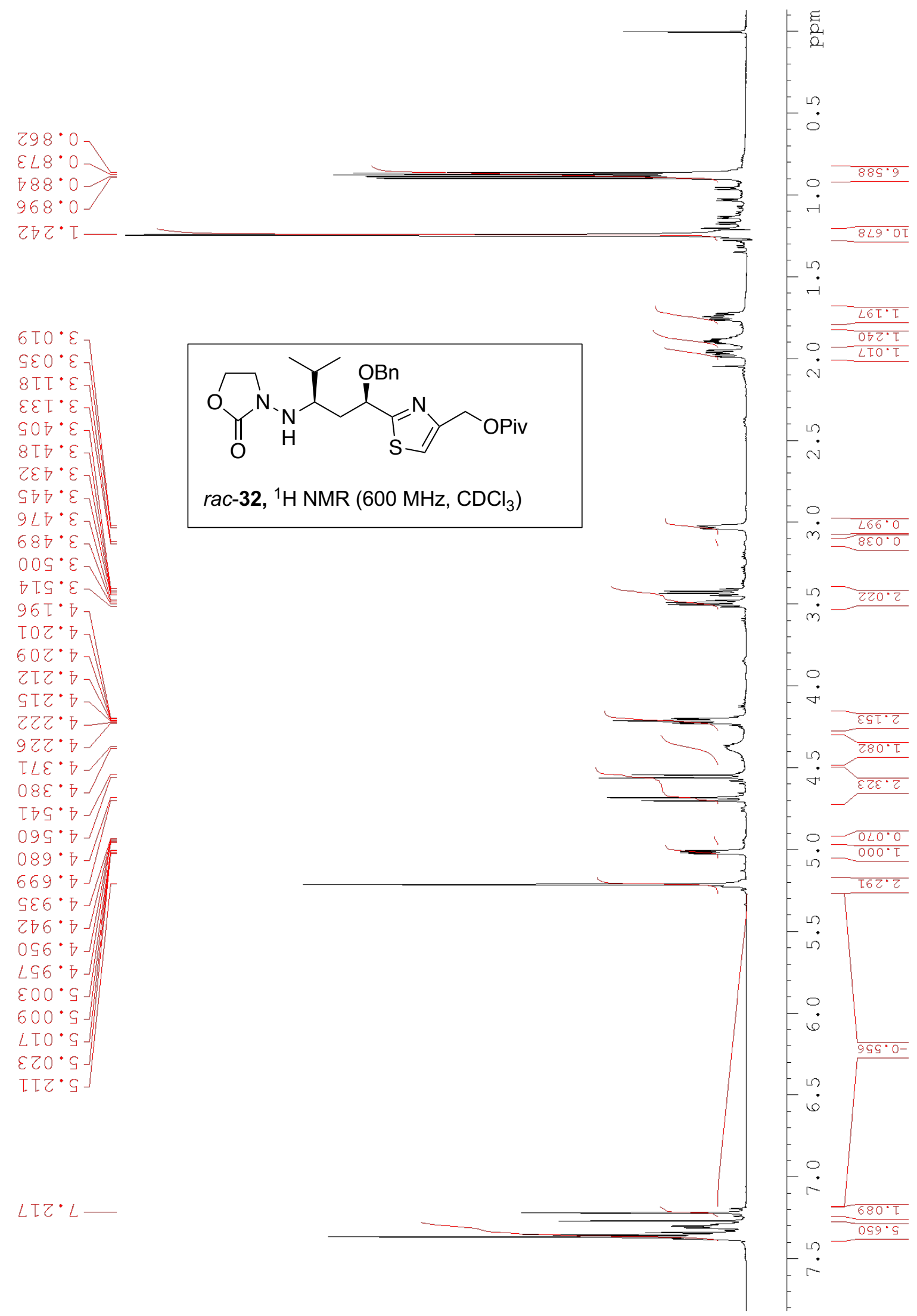




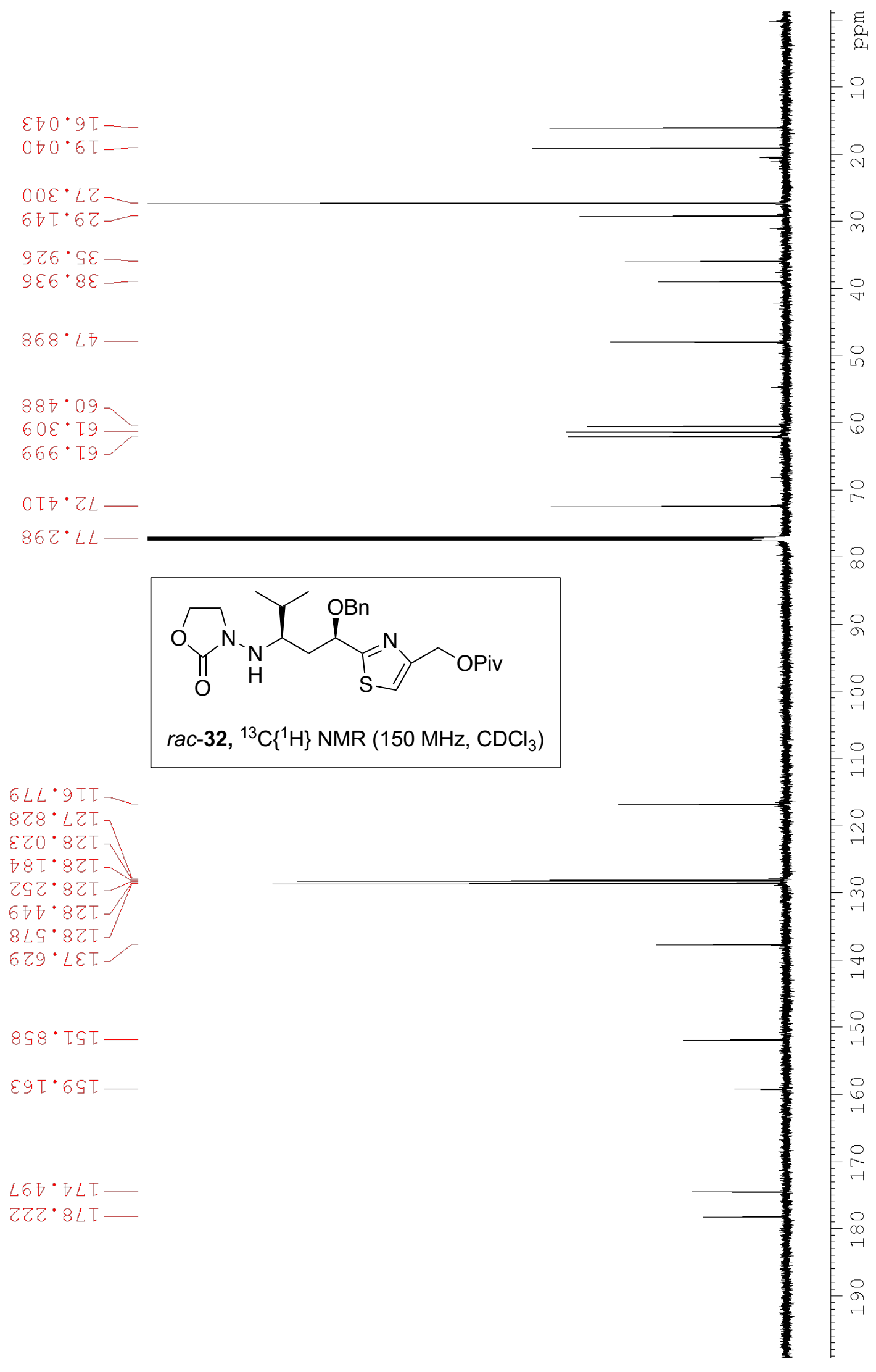




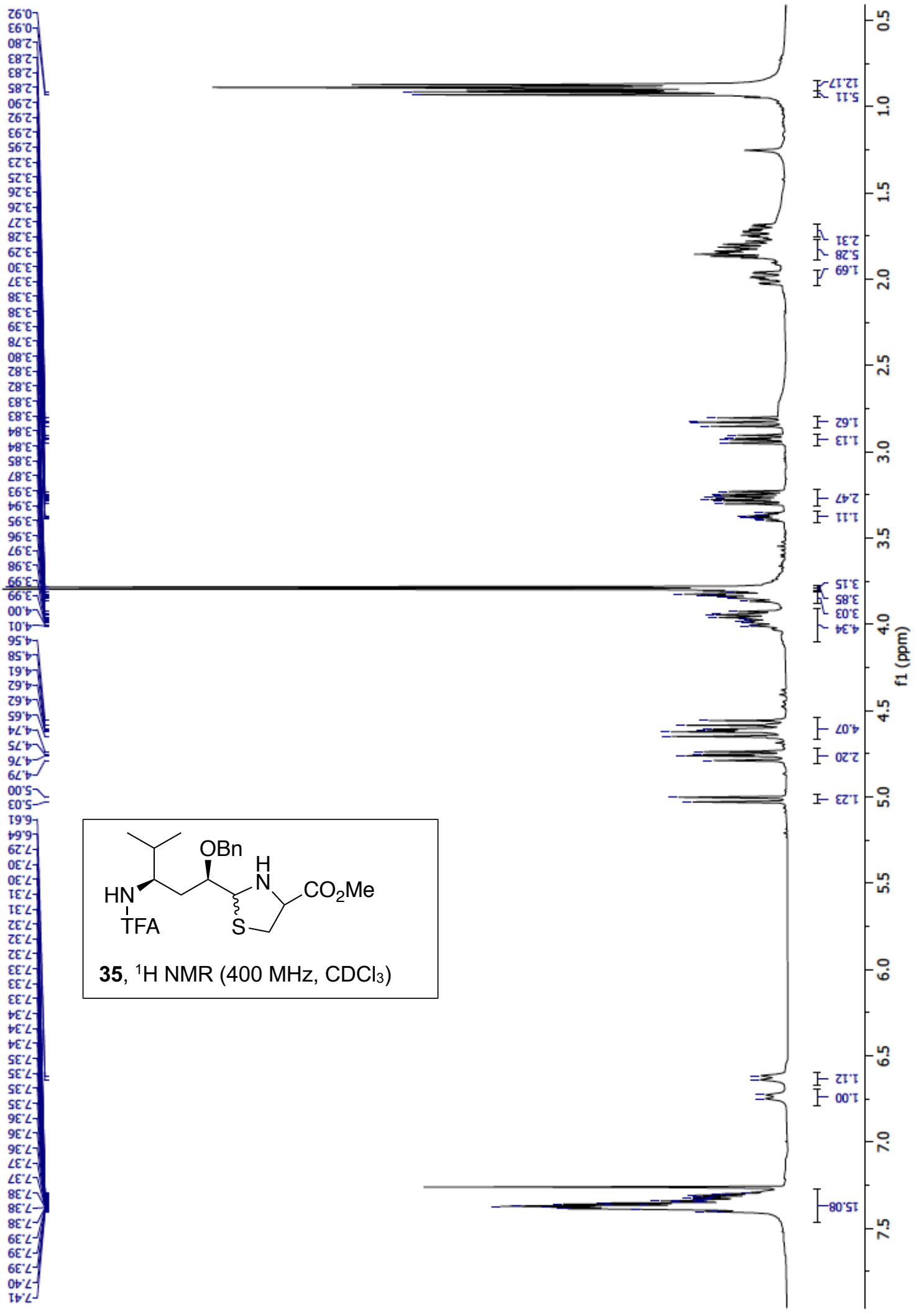




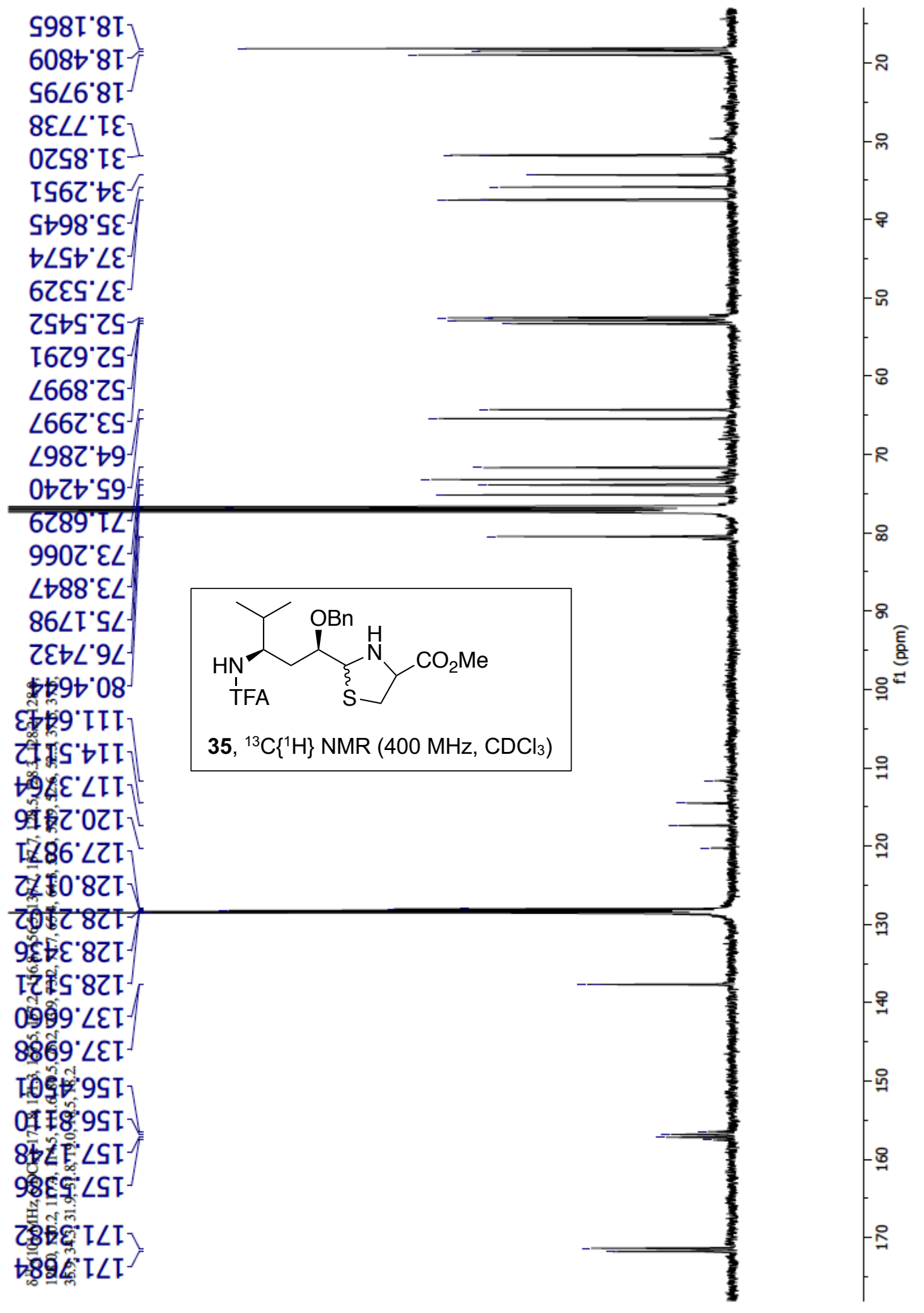




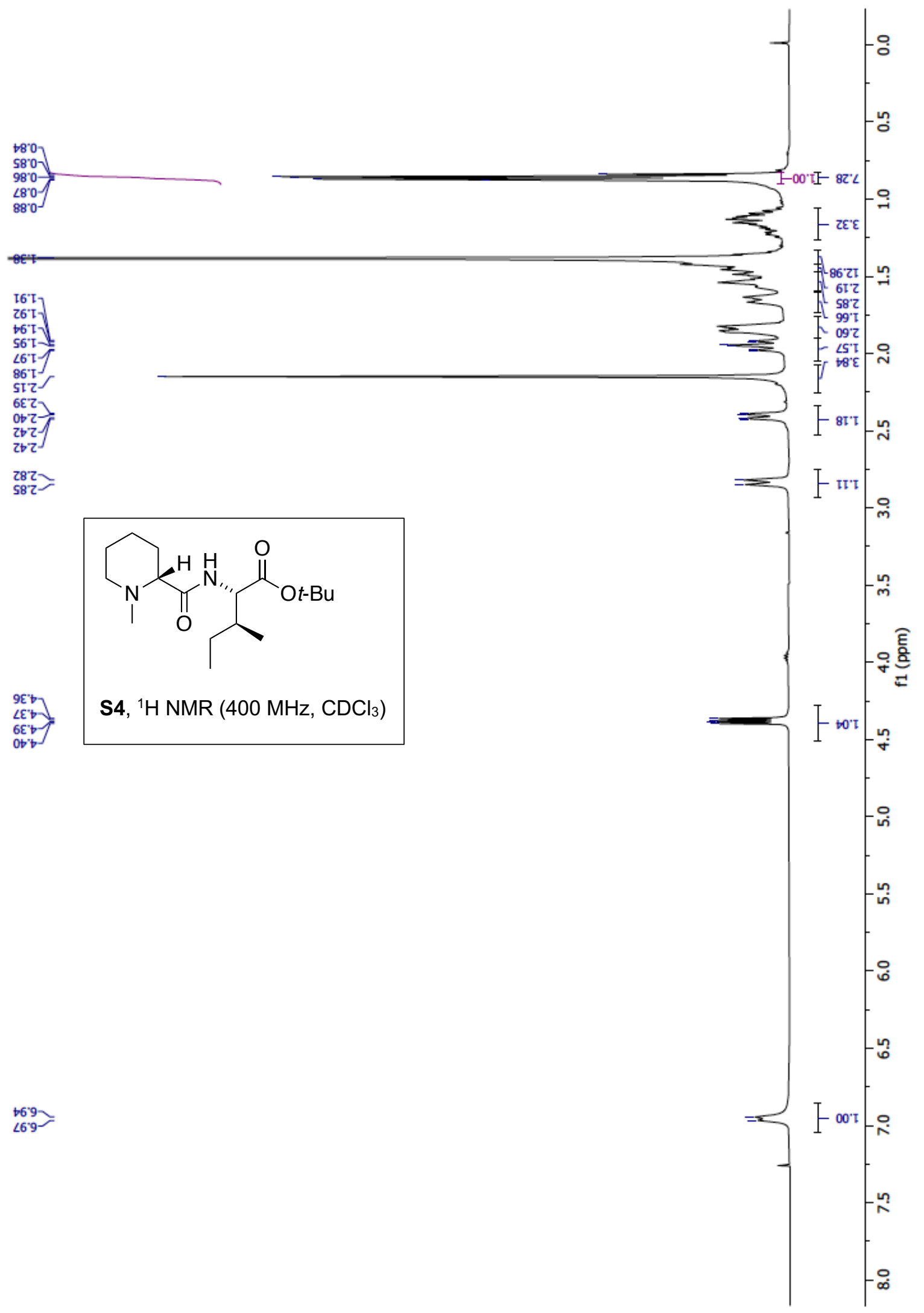




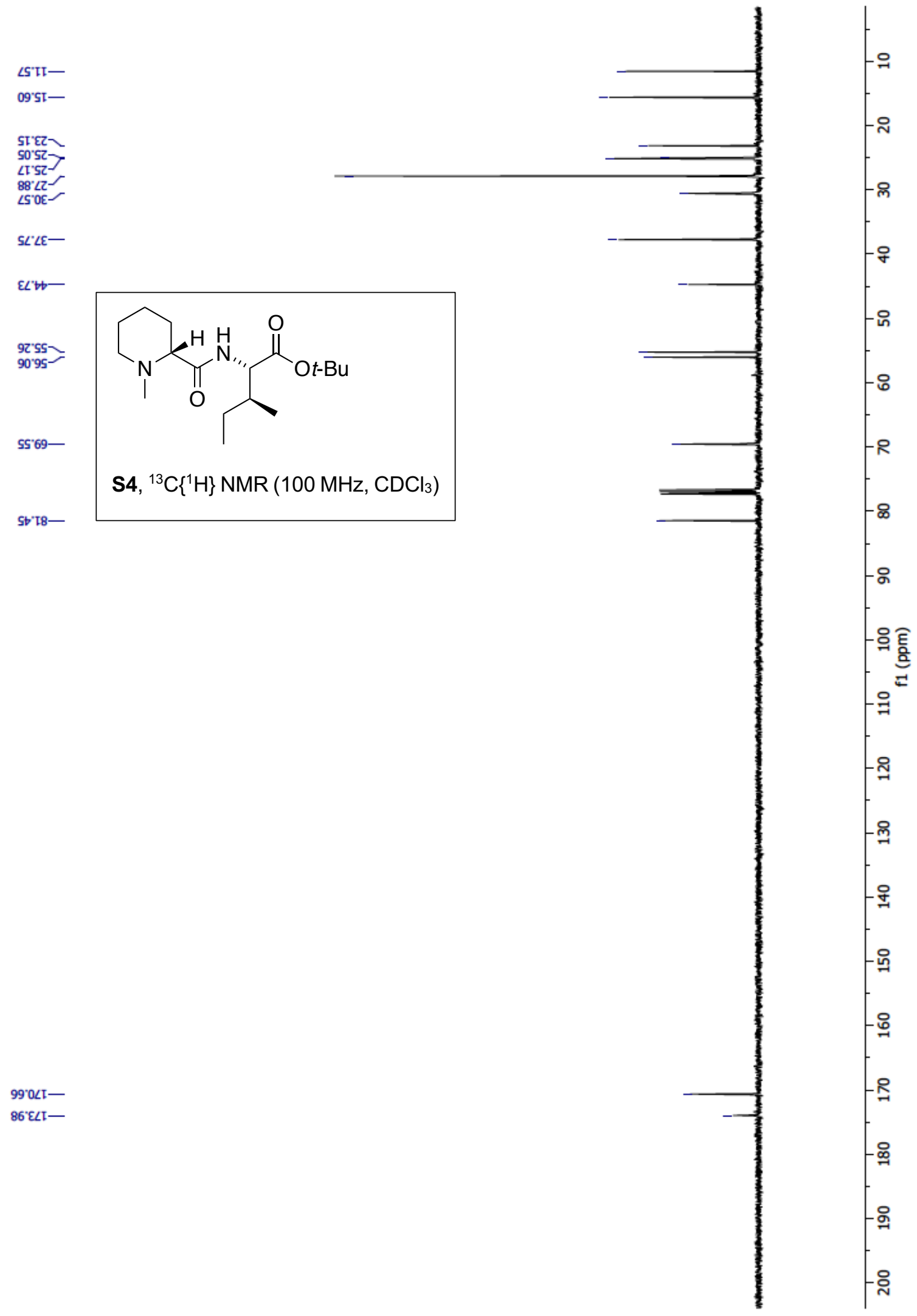




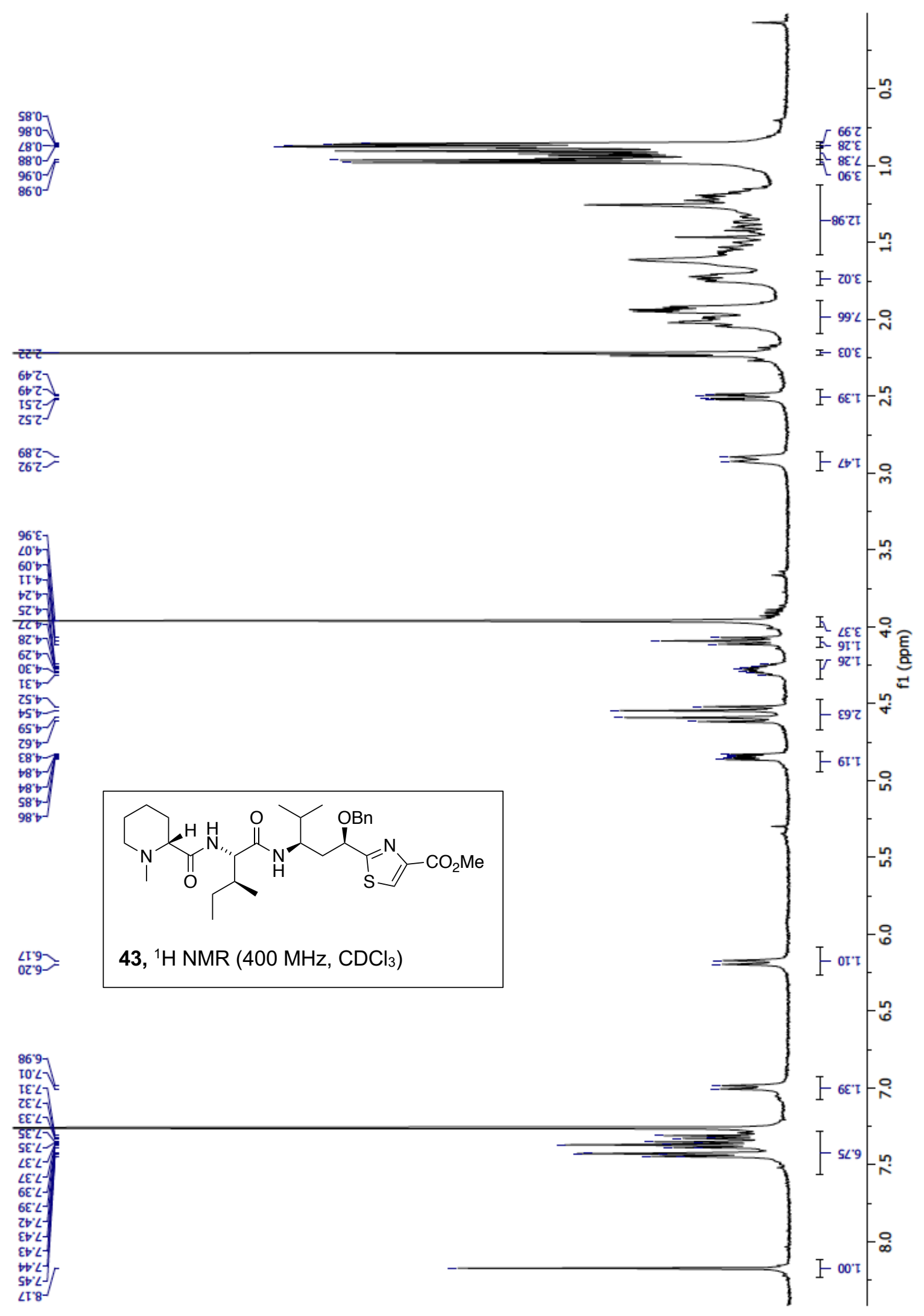




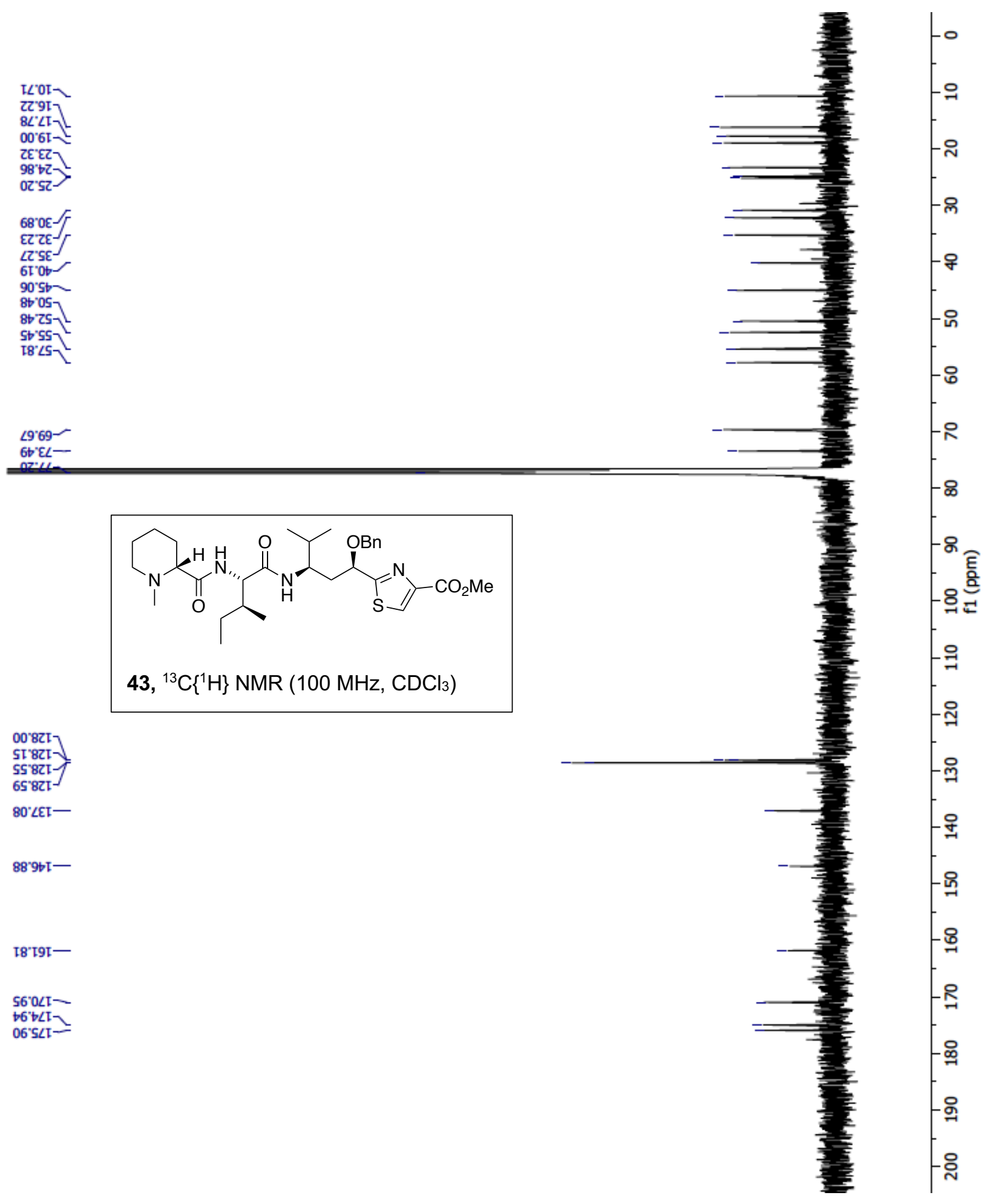




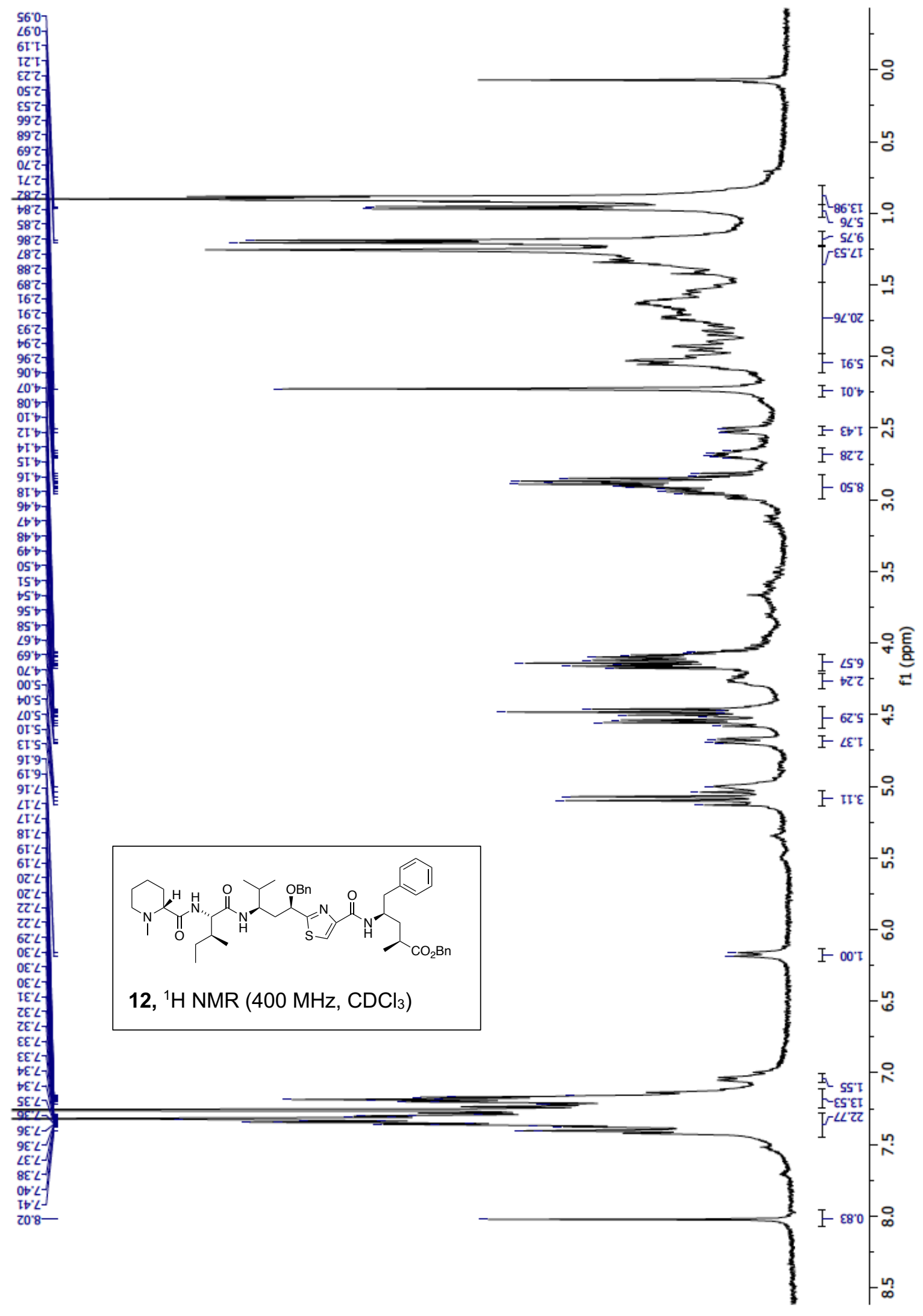




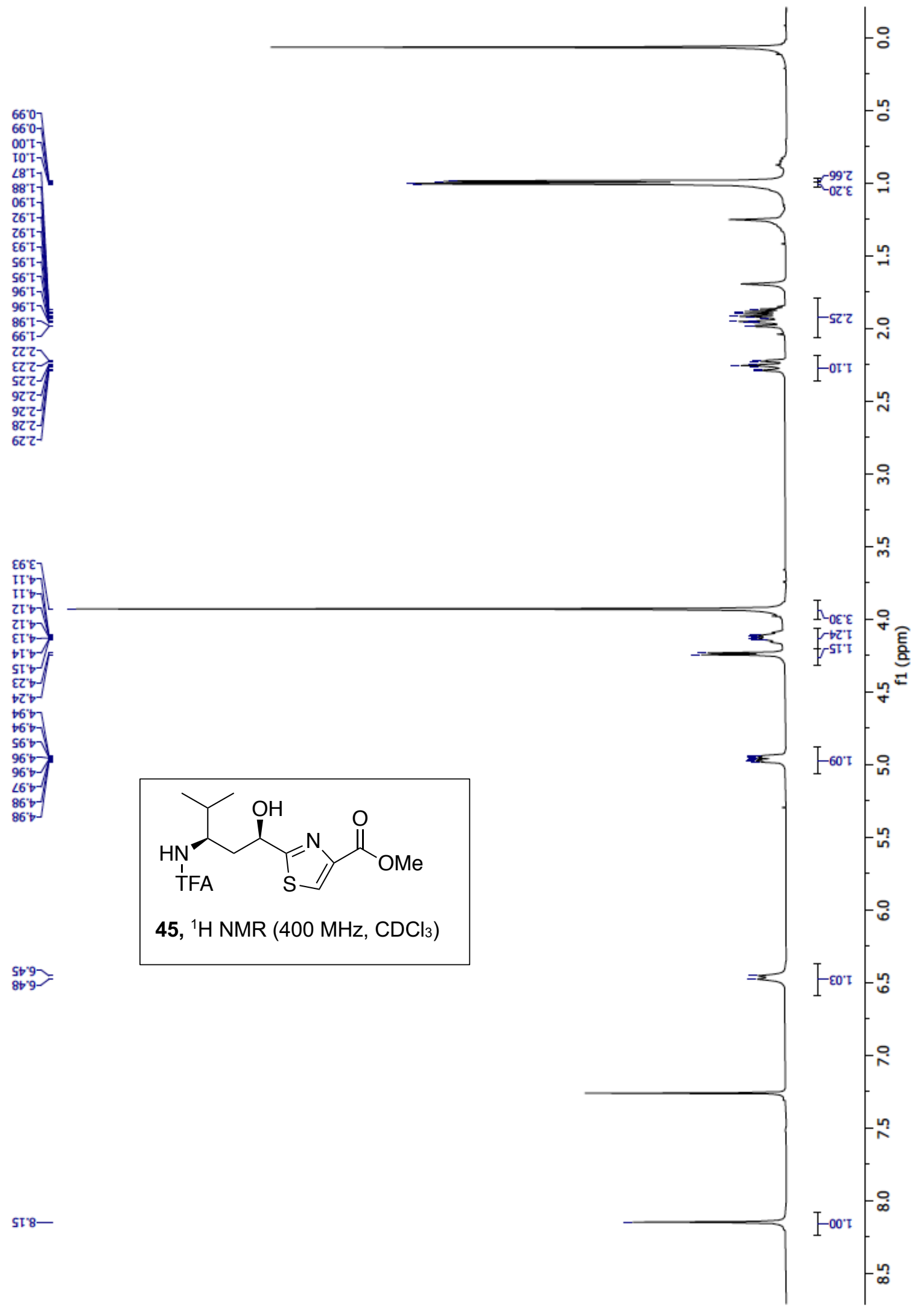




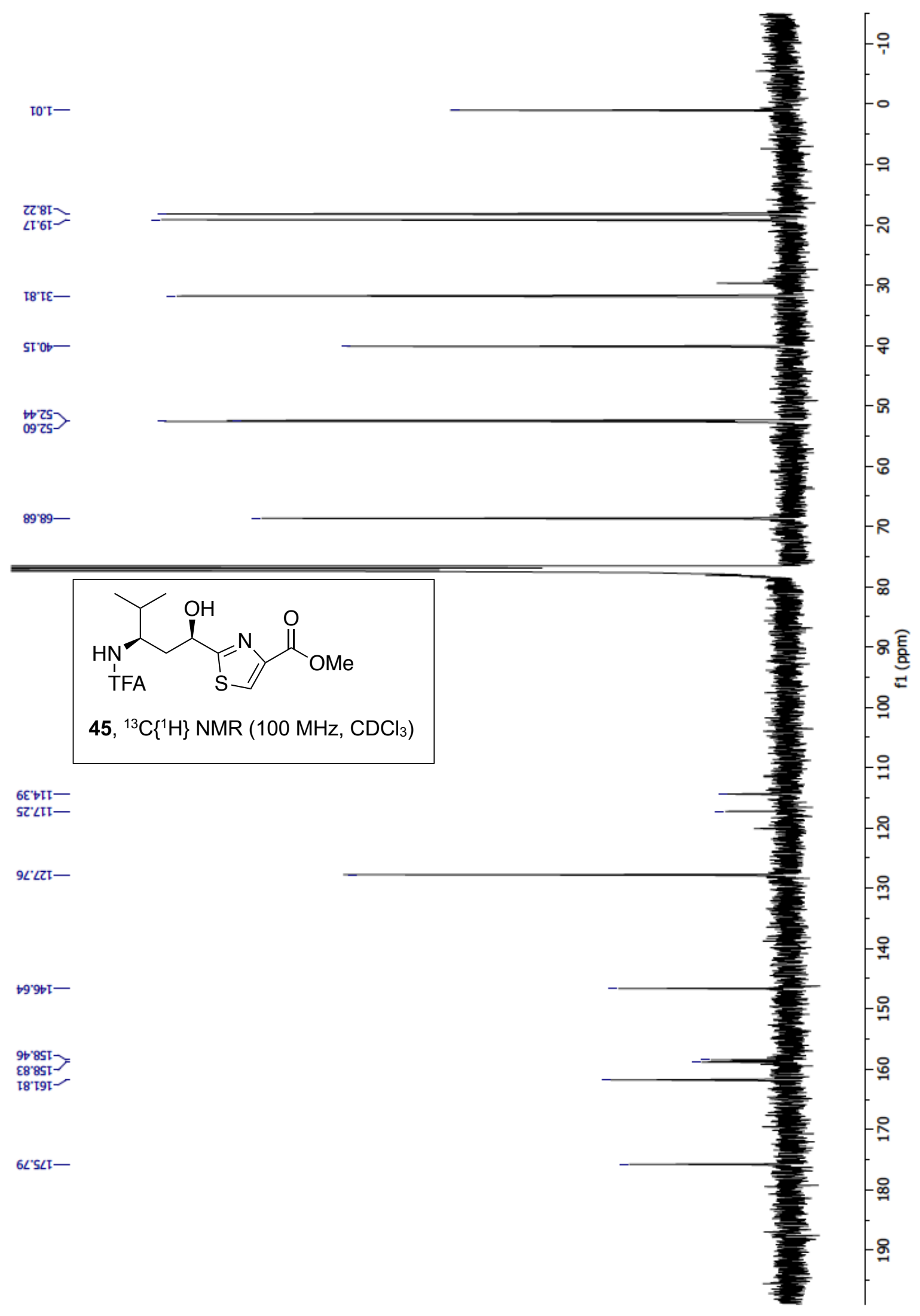




\section{Enantiomer Ratio and Configuration Assignment of $(R)-19$}

Compound ( $R$ )-19 was obtained via Keck allylation, as shown below. The enantiomer ratio (10:1) and configuration assignment were determined via the Mosher ester prepared from $(S)$-MTPA-Cl. The ${ }^{1} \mathrm{H}$ NMR spectrum is provided on the following page.

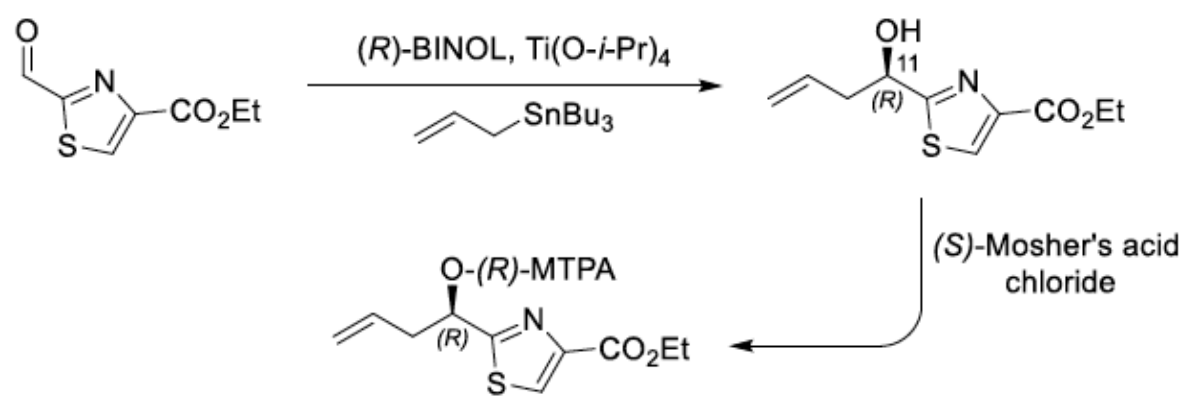

\begin{tabular}{cccc}
\hline \multirow{2}{*}{$\begin{array}{c}\text { Major } \\
\text { diastereomer }\end{array}$} & $\begin{array}{c}\text { Minor } \\
\text { diastereomer }\end{array}$ & \multicolumn{2}{c}{$\Delta \delta\left(=\delta_{\text {major }}-\delta_{\text {minor }}\right)$} \\
\cline { 3 - 5 } & $\mathrm{ppm}$ & $\mathrm{Hz}(400 \mathrm{MHz})$ \\
\hline .147 & 8.087 & 0.06 & 24 \\
4.433 & 4.423 & 0.01 & 4 \\
1.408 & 1.400 & 0.008 & 3.2 \\
$5.70-5.60$ & $5.80-5.70$ & -0.10 & -40 \\
$5.08-5.00$ & $5.19-5.11$ & -0.11 & -44 \\
3.542 & 3.580 & -0.038 & -15
\end{tabular}

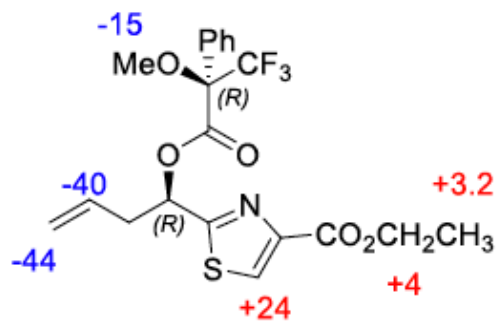




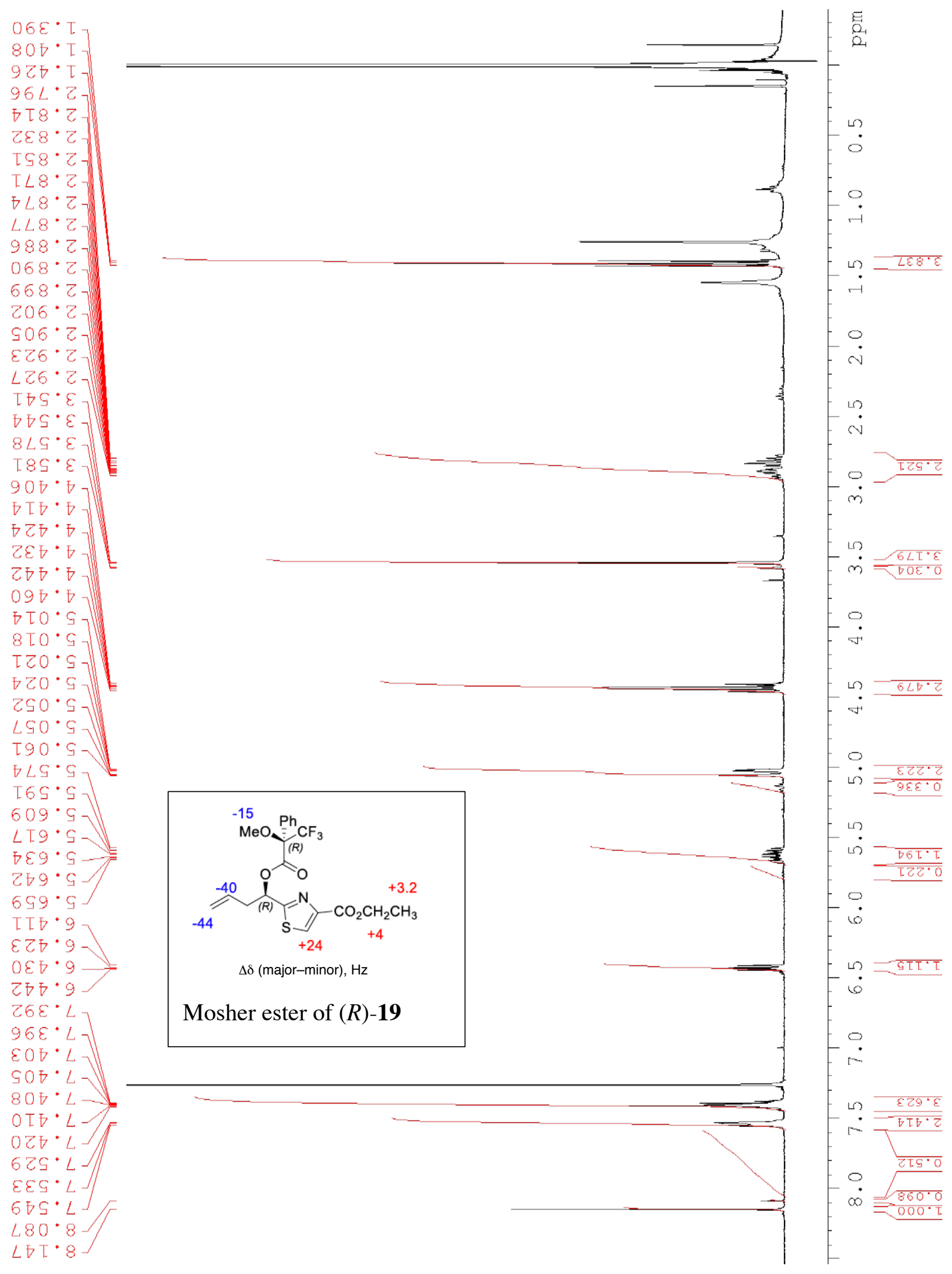

